\title{
Parametric Modeling Approach for Economic and Environmental Life Cycle Assessment of Medium-Duty Truck Electrification
}

Dong-Yeon Lee $^{\mathrm{a},{ }^{*}}$ and Valerie M. Thomas ${ }^{\mathrm{b}, \mathrm{c}}$

${ }^{a}$ Energy Systems Division, Argonne National Laboratory, 9700 South Cass Avenue, Lemont, IL 60439

${ }^{b}$ School of Industrial and Systems Engineering, Georgia Institute of Technology, 755 Ferst Drive NW, Atlanta, GA 30332-0205

'School of Public Policy, Georgia Institute of Technology, 685 Cherry Street, Atlanta, GA 30332-0345

* Corresponding author. E-mail: dongyeon.lee@anl.gov 


\section{Graphical Abstract}
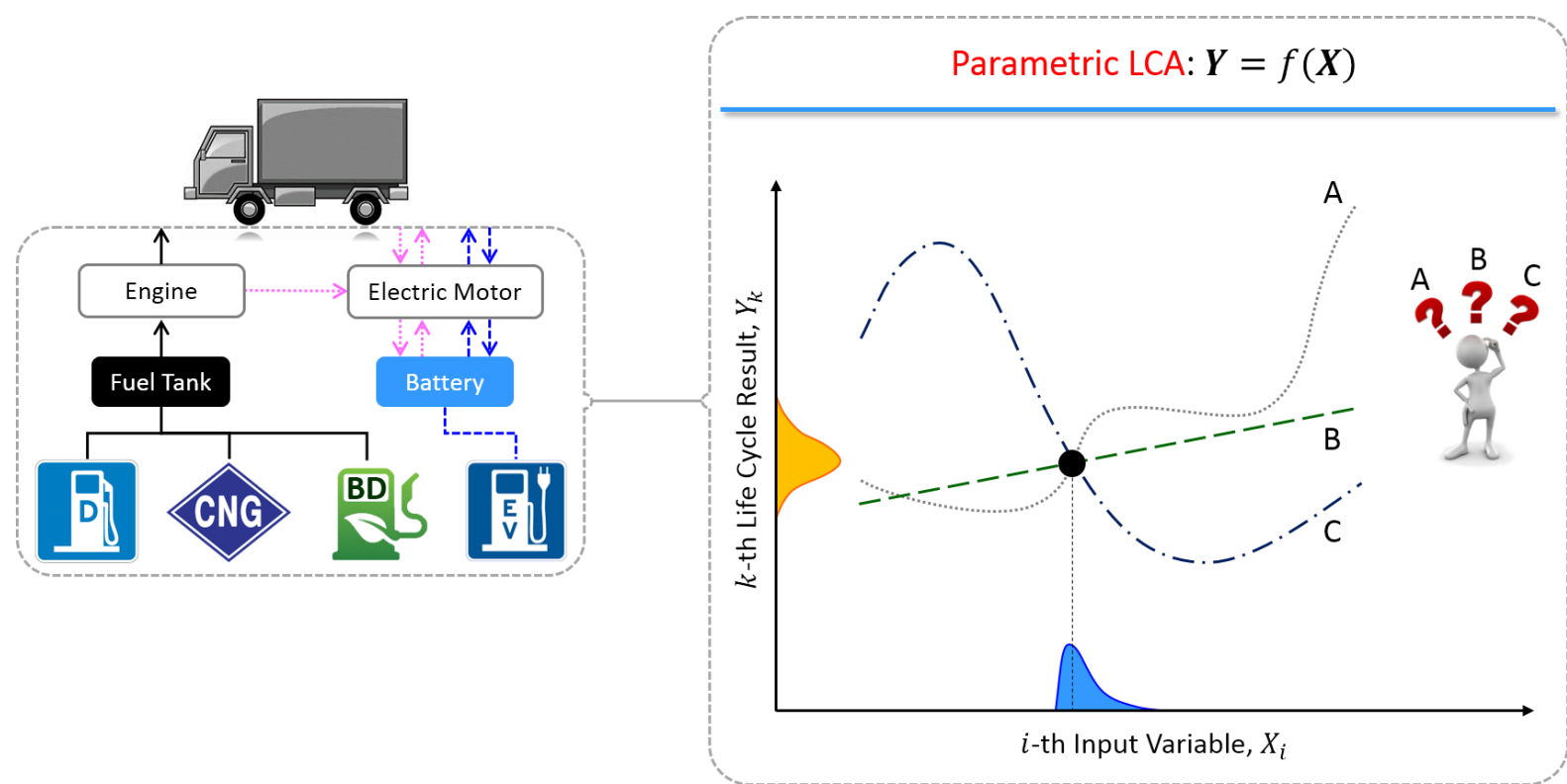


\section{Abstract}

Using a parametric modeling approach, we evaluate economic and environmental life cycle trade-offs of medium-duty electric trucks in comparison with nine non-electric technologies (e.g., conventional diesel, biodiesel, compressed natural gas, etc.) for U.S. model year 2015. Life cycle results for electric trucks vary strongly with weighted positive kinetic energy, whereas those for non-electric trucks vary the most with average trip speed. Our parametric life cycle assessment models explain $91 \%-98 \%$ of the variability in life cycle inventory and impact assessment results, revealing "how" and "why" the tradeoffs of truck electrification change with different input conditions.

In terms of cost, whether total cost of ownership or also including health and climate impact costs, model year 2015 battery electric trucks in severe applications such as urban driving provide positive and robust net benefits in many areas of the U.S. However, for typical operations, petroleum diesel with idle reduction or hybrid-electric technology provide the largest overall life cycle cost benefit.

Battery electric, idle reduction, and hybrid trucks emit lower life cycle greenhouse gas emissions across the board in comparison with the other technologies. Despite lower carbon-intensity, electric trucks tend to be water-intensive because of cooling water consumption for thermo-electric power plants. Hybrid trucks create higher NOx emissions and thus larger associated environmental impacts. Idle reduction is beneficial to urban-type applications. Compressed natural gas trucks are the least waterintensive but may not reduce greenhouse gas emissions. Using marginal rather than average factors for electric grid emissions calculations doesn't change the overall life cycle comparisons. Improving driving behavior has universally positive effects for which the exact magnitude and sensitivity depend on environmental impact indicators and technologies.

Keywords: electric vehicles; life cycle trade-offs; robustness; parametric analysis; marginal electric grid; water-energy nexus

(Word Count: Abstract: 271, Main text: 7,611, Total: 7,882 <8,000 words) 


\section{Abbreviations}

B20 Petroleum diesel blended with $20 \%$ of biodiesel by fuel volume

CNG Compressed natural gas

CPP Clean Power Plan

DPF Diesel particulate filter

EVSE Electric vehicle supply equipment

GWP20 Global warming potential over 20-year time horizon

GWP100 Global warming potential over 100-year time horizon

HD-UDDS Heavy-Duty Urban Dynamometer Driving Schedule

HTUF-6PDDS Hybrid Truck Users Forum Class 6 Parcel Delivery Driving Schedule

LCA Life cycle assessment

MDT Medium-duty truck

NPV Net present value

PKE Positive kinetic energy

OLCC Overall life cycle cost, sum of total cost of ownership and air emissions damage cost

$\mathrm{PCl} \quad$ Percentage change impact

SCR Selective catalytic reduction

$\mathrm{SOC} \quad$ State of charge

TCO Total cost of ownership

TWC Three-way catalyst

VKT Vehicle kilometers traveled

WPKE Weighted positive kinetic energy, product of vehicle weight and positive kinetic energy 


\section{Introduction}

\subsection{Medium-duty Truck Electrification}

Today's average U.S. automobiles are about twice as efficient as those in the 1970s (EPA 2015a). In contrast, the average fuel efficiency of current medium-duty trucks weighing $4.5-12$ metric tons $(10,001-26,000$ pounds) is more or less the same as that of four decades ago (BTS 2015). The new regulations for medium- and heavy-duty vehicles (Federal Register 2015a; EPA 2016) will increase fuel efficiency and reduce air emissions in coming years. Alternative truck technologies can also help improve overall energy efficiency and reduce environmental impacts, for example, battery electric (Lee et al. 2013), hybrid-electric (Bachmann et al. 2015), natural gas, biodiesel, etc.

A number of studies have identified the benefits and limitations of different medium-duty truck (MDT) technologies (Nellums et al. 2003; Delorme and Karbowski 2010; Barnitt 2011; Burton et al. 2013a; Lee et al. 2013; Bachmann et al. 2015). What all these studies indicate is that there are "conditional" tradeoffs. For instance, the advantage of the electric-drive technology is maximized in city-type drive cycles (i.e., speed-time profiles or schedules), but the benefit diminishes in high speed driving conditions that are typical for highway or long-haul operations (Lee et al., 2013). On the other hand, what these previous MDT studies are lacking is the prediction capability of life cycle trade-offs varying with input conditions. Whether electric or non-electric MDT life cycle assessment (LCA), most studies (Lee et al. 2013; Bachmann et al. 2015) rely on average or case-specific parameters, conditions, and assumptions. It is hard to come by a study that systematically predicts and explains life cycle trade-offs of different MDT technologies with changing input conditions as operationalized variables. Here we develop and propose a parametric LCA for evaluating conditional trade-offs of MDT technologies, focusing on electric trucks.

\subsection{Parametric Life Cycle Assessment Approach}

\subsubsection{Rationale}

Vehicle energy use and air emissions inherently depend on vehicle dynamics which are a function of drive cycle characteristics (e.g., speed and acceleration), vehicle attributes (e.g., vehicle mass, aerodynamic drag coefficient, etc.), roadway conditions (e.g., road grade), etc. Although the exact degree or pattern of the impact can vary with technology, the dependency on drive or duty cycles is universal - all being governed by the laws of physics. Here, drive cycles refer to the profiles or schedules 
of speed and time, and duty cycles are time profiles of speed as well as vehicle weight and/or road grade. Most of the time, more severe drive or duty cycles will increase energy consumption and emissions, regardless of vehicle technologies. Numerous studies have shown that vehicle energy use and emissions can be predicted and/or explained with drive or duty cycle characterization parameters. Examples include Watson et al. (1983), Ross (1994), André (2004), and Clark et al. (2010). Here we apply this logic to the economic and environmental LCA of medium-duty freight truck technologies. In doing so, we utilize a new parameter that can explain electric trucks' unique energy consumption pattern more effectively. Furthermore, compared to previous freight truck LCA studies that focused on carbon footprint (Lee et al., 2013; Bachmann et al., 2015), we provide a more comprehensive environmental impact assessment including water consumption and air pollutants emissions.

\subsubsection{Physics Simulation}

The core building block of a parametric LCA is physics simulation run over the entire range of input variables. We use a high fidelity physics simulation software as a substitute for the complex real world vehicle operation. The challenge is that physics simulations have a time resolution of milliseconds, while LCA-based decision-making is generally for a multi-year product life time scale. A reduced model is needed to bridge the time scale difference. We use multiple linear regression to develop a reduced-form parameterization of the high resolution physics model.

Although Lee et al. (2013) used a similar high fidelity physics simulation for a truck life cycle study, only several samples were utilized. And unlike previous studies (Lee et al. 2013; Bachmann et al. 2015), we incorporate spatial heterogeneity in input conditions (e.g., climate) and show how to deal with them in a parametric manner. Most importantly, our approach differs in three ways from existing linear regression-based life cycle studies (for example, Elgowainy et al. 2014; Steinmann et al. 2014). First, we use an underlying physics model to develop the life cycle model. Second, our approach is based on thousands of detailed physics simulation runs and therefore enables sweeping through entire decision space, minimizing assumptions on distributions. Third, our study addresses the complete life cycle instead of specific life cycle stages such as well-to-pump (upstream) or well-to-wheel (fuel cycle).

\subsubsection{Reduced Model - Generic Form}

Based on vehicle dynamic simulation along with parameterization, we develop the following generic life cycle inventory prediction models using linear regression, written as the product of powers: 
$\widehat{Y}=\exp \left(\hat{\beta}_{0}\right) \cdot \prod_{i=1}^{I}\left[\exp \left(X_{i}\right)\right]^{\widehat{\beta}_{i}} \cdot \prod_{j=1}^{J} X_{j}^{\widehat{\beta}_{j}} \cdot \prod_{k=1}^{K}\left[\exp \left(\frac{1}{X_{k}}\right)\right]^{\widehat{\beta}_{k}}$

where $\hat{Y}^{\prime}$ s are life cycle results (e.g., energy consumption, air emissions, smog formation, etc.); $X^{\prime}$ s are independent variables (or predictors) (e.g., average trip speed, payload, weighted positive kinetic energy, etc.); and $\hat{\beta}$ 's are the multiple linear regression parameters estimated based on the ordinary least squares method. On top of these generic models, scaling factors for road grade and climate condition can be multiplied. More details on dependent and independent variables as well as correction factors are provided in a later section. Using the generic models in Eq. (1), the complicated vehicle dynamic and emissions simulations do not need to be run over and over again. Instead, one can simply plug the characterization values into Eq. (1). More details are provided in Methods section.

\subsubsection{Utility}

Our parametric LCA extends conventional LCA and previous MDT life cycle studies in that we present LCA results with generic, causal equations, whereas previous life cycle studies report point estimates (averages or case-specific results) oftentimes with ranges. All in all, parametric LCA brings four advantages:

- First, parametric LCA enables systematic prediction of life cycle trade-offs and shows under which conditions a technology provides the largest benefits. This can help identify strategic niche applications for a given technology and assign electric trucks for the most suitable operating conditions and routes based on holistic information as to the benefits and trade-offs over a range of operating conditions.

- Second, parametric LCA reveals to what extent the benefits are robust under numerous conditions and uncertainties. New technologies will ultimately have to compete with established technologies for general operations rather than just for limited or niche applications. As we sweep through entire input ranges with a parametric LCA approach, we can identify necessary conditions for new technology benefits to be robust.

- Third, the parametric approach requires minimal input (e.g., total distance traveled divided by travel time) to evaluate life cycle results and thus alleviates the burden of input and output data availability.

- Fourth, the parametric LCA explains how and why impacts change. For trucks it explains not only how overall energy consumption varies with input conditions, but also why medium- and heavyduty electric vehicles show totally different energy use patterns compared to light-duty electric 
vehicles; and why this is not the case for non-electric vehicles. Explaining how and why result vary helps generalize life cycle research methods and findings.

\section{Material and Methods}

\subsection{Life Cycle Assessment Goal and Scope}

The goal of our life cycle assessment (LCA) is to compare medium-duty freight truck technologies. The comparative evaluation criteria are cost, energy efficiency, fresh water consumption, and air emissions impacts (i.e., global warming, acidification, eutrophication, smog formation, and monetized human health and ecological damage). As shown in the system boundary diagram in Figure 1, our life cycle air emissions inventory includes greenhouse gases $\left(\mathrm{GHGs}-\mathrm{CO}_{2}, \mathrm{~N}_{2} \mathrm{O}\right.$, and $\left.\mathrm{CH}_{4}\right)$, carbon monoxide (CO), ammonia $\left(\mathrm{NH}_{3}\right)$, nitrogen oxides ( $\left.\mathrm{NOx}\right)$, particulate matter $\left(\mathrm{PM}_{2.5}\right.$ and $\left.\mathrm{PM}_{10}\right)$, sulfur dioxide $\left(\mathrm{SO}_{2}\right)$, and volatile organic compounds (VOC). We also account for $\mathrm{PM}_{2.5}$ and $\mathrm{PM}_{10}$ emissions from tire and brake wear. Once these air emissions are tallied, we assess their midpoint life cycle environmental impacts based on TRACI 2.1 (Bare et al. 2002; Bare 2011, 2012) and the 20- and 100-year global warming potential (GWP) from the Fifth Assessment Report (AR5) of the Intergovernmental Panel on Climate Change (IPCC 2013). As for life cycle water consumption, we present our result in gallons of fresh water

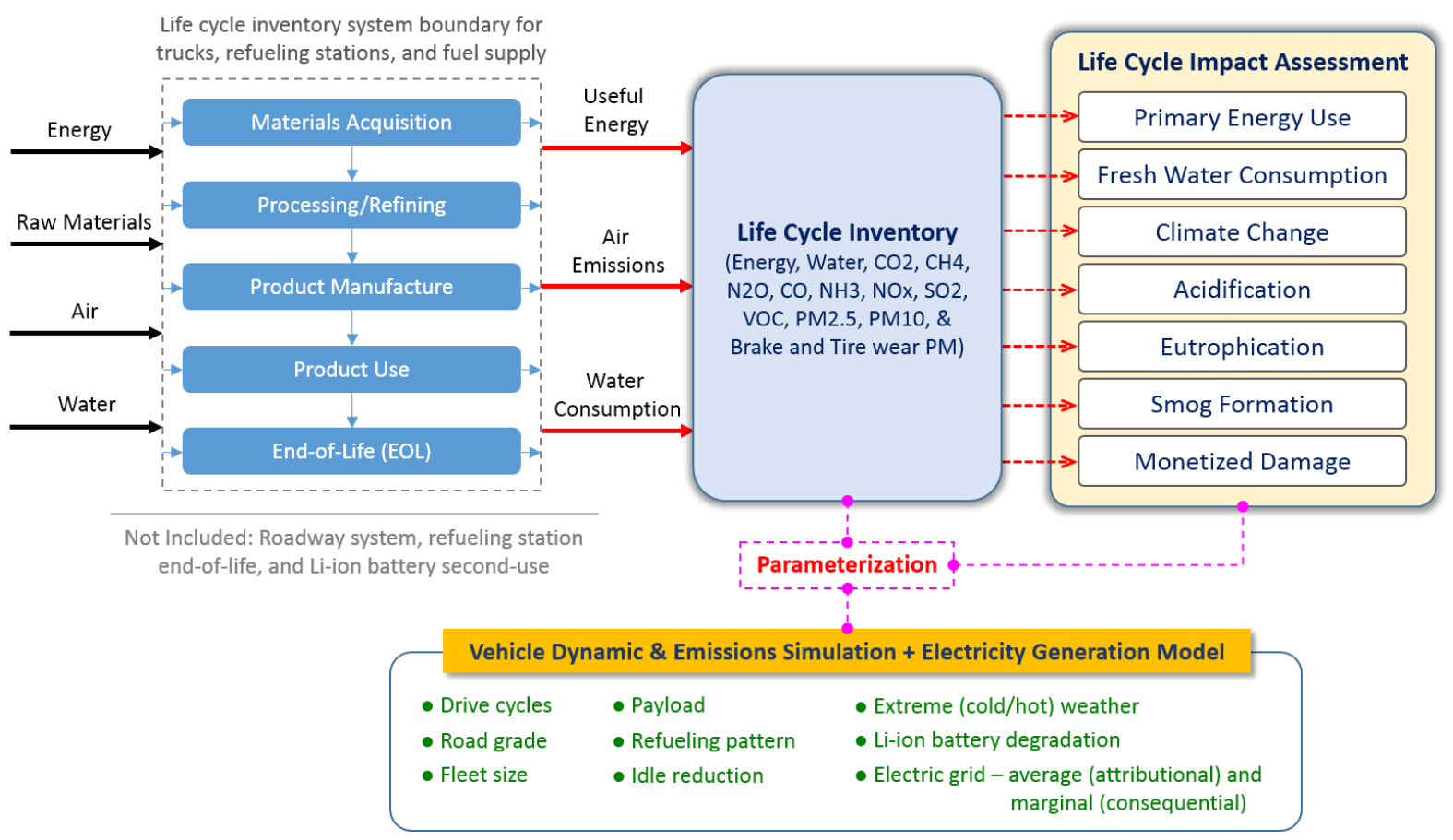

Figure 1. Framework and System Boundary Diagram for Medium-Duty Truck Parametric LCA. 
used. For endpoint life cycle impact assessment, we utilize the APEEP model (Muller 2011) and evaluate monetized air pollutants emissions damage cost combined with social cost of carbon emissions (The White House 2013).

The target audience of our LCA includes policy makers, the general public, fleet managers, and LCA researchers. Our study aims to improve understanding of both the promise and limitations of mediumduty truck (MDT) electrification under various operating conditions and in relation to competing truck technologies. The product systems to be compared are 2015 Model Year (MY) medium-duty trucks, specifically, gross vehicle weight rating (GVWR) class 6 (8.8 - 11.8 metric tons or 19,501-26,000 lb) goods movement trucks. Table 1 summarizes the vehicle specifications. The functional unit is the product of weight of freight moved (payload) and distance traveled (i.e., ton-km). To comply with this definition, whenever we present the results per distance traveled for simplicity, we provide the vehicle weight condition tested so that per-ton-km results can be derived. We compare three different vehicle technologies - internal combustion engine (ICE), hybrid-electric, and battery electric - for four different fuel types - conventional diesel (or ultra-low sulfur diesel, ULSD), compressed natural gas (CNG), biodiesel (BD), and electricity. Under the Renewable Fuel Standard (RFS), conventional diesel fuel in the U.S. currently contains approximately $3 \%$ biodiesel by volume, and up to a $5 \%$ biodiesel blend (or B5) can be called or used as "conventional" diesel without separate biodiesel labeling at the pump. In our analysis, biodiesel refers to petroleum diesel blended with $20 \%$ soybean-based biodiesel by fuel volume (or B20). Most of recent diesel engines and trucks are designed to handle B20.

\subsection{Data Sources and Methods}

\subsubsection{Vehicle Production and Refueling Station}

For vehicle and parts production and repairs for the truck technologies specified in Table 1, material-bymaterial energy use, water consumption, and emissions factors from the GREET model (ANL 2015) were applied to truck material composition data (Gaines et al. 1998) modified to reflect more recent vehicular materials composition (Davis \& Diegel 2015). For tires and fluids (e.g., engine oils, transmission oils, coolant, etc.), default values in the GREET model were used with adjustments based on the difference between light-duty vehicles in GREET and medium-duty trucks (e.g., the number of tires, tire size, engine displacement, frontal area, weight, etc.). Compressed natural gas (CNG) cylinders, two Type-3 72 -inch cylinders (Freightliner 2014), are not specifically addressed in the GREET model. For this, we assume a 70-30 share of aluminum for the metal liner and carbon fiber for an overwrap (Luxfer 2013). We use 
Table 1. Modeled Truck Specifications

\begin{tabular}{|c|c|c|c|c|c|c|}
\hline & Diesel & $\begin{array}{l}\text { Biodiesel } \\
\text { (B20) }\end{array}$ & $\begin{array}{l}\text { Diesel } \\
\text { or Biodiesel } \\
\text { Hybrid }\end{array}$ & CNG & $\begin{array}{l}\text { CNG } \\
\text { Hybrid }\end{array}$ & Electric \\
\hline Model year & \multicolumn{6}{|c|}{2015} \\
\hline Vehicle weight class & \multicolumn{6}{|c|}{6} \\
\hline Manufacturer & \multicolumn{5}{|c|}{ Freightliner } & SEV \\
\hline $\begin{array}{l}\text { Gross vehicle } \\
\text { weight (ton) }\end{array}$ & \multicolumn{6}{|c|}{11.8 (curb weight + payload capacity) } \\
\hline Overall size $(\mathrm{m})$ & \multicolumn{6}{|c|}{8.8 (length) x 2.2 (width) x 2.8 (height) } \\
\hline Curb weight (kg) & 7700 & 7700 & 7980 & 7960 & 8240 & 6830 \\
\hline Payload cap. (kg) & 4100 & 4100 & 3820 & 3840 & 3560 & 4970 \\
\hline $\begin{array}{l}\text { Engine model \& } \\
\text { power }(k W)\end{array}$ & \multicolumn{3}{|c|}{$\begin{array}{c}\text { Cummins ISB 6.7L } \\
(186 \mathrm{~kW})\end{array}$} & \multicolumn{2}{|c|}{$\begin{array}{l}\text { Cummins ISL G250 } \\
(186 \mathrm{~kW})\end{array}$} & - \\
\hline $\begin{array}{l}\text { Aftertreatment } \\
\text { system }\end{array}$ & \multicolumn{3}{|c|}{$\begin{array}{l}\text { Diesel Particulate Filter (DPF) and } \\
\text { Selective Catalytic Reduction (SCR) }\end{array}$} & \multicolumn{2}{|c|}{ Three-Way Catalyst (TWC) } & - \\
\hline $\begin{array}{l}\text { Electric motor } \\
\text { power (kW) }\end{array}$ & - & - & $\begin{array}{c}44 \mathrm{~kW} \\
\text { Induction }\end{array}$ & - & $\begin{array}{c}44 \mathrm{~kW} \\
\text { Induction }\end{array}$ & $\begin{array}{l}120 \mathrm{~kW} \\
\mathrm{PMSM}\end{array}$ \\
\hline Transmission & \multicolumn{2}{|c|}{$\begin{array}{c}\text { 6-speed } \\
\text { Allison } 2100 \mathrm{HS}\end{array}$} & $\begin{array}{l}\text { 6-speed } \\
\text { Eaton Fuller }\end{array}$ & $\begin{array}{l}\text { 6-speed } \\
\text { Allison } \\
2100 \mathrm{HS}\end{array}$ & $\begin{array}{l}\text { 6-speed } \\
\text { Eaton } \\
\text { Fuller }\end{array}$ & $\begin{array}{l}\text { Single-gear } \\
\text { reduction }\end{array}$ \\
\hline $\begin{array}{l}\text { Traction battery } \\
\text { capacity (kWh) }\end{array}$ & - & - & $\begin{array}{c}1.9 \text { kWh } \\
\text { (Hitachi Li- } \\
\text { ion) }\end{array}$ & - & $\begin{array}{c}1.9 \mathrm{kWh} \\
\begin{array}{c}\text { (Hitachi Li- } \\
\text { ion) }\end{array} \\
\end{array}$ & $\begin{array}{l}80 \text { or } 120 \\
\text { kWh (Li- } \\
\text { ion) }\end{array}$ \\
\hline Fuel tank & \multicolumn{3}{|c|}{$\begin{array}{c}\text { Single aluminum tank } \\
\text { (50 DGE, diesel gallon equivalent) }\end{array}$} & \multicolumn{2}{|c|}{$\begin{array}{c}2 \text { Type-3 Cylinders } \\
\text { (17 DGE) }\end{array}$} & - \\
\hline Refueling option & \multicolumn{3}{|c|}{ Gas station } & \multicolumn{2}{|c|}{ CNG station } & $\begin{array}{c}\text { AC Level } 2 \\
15 \mathrm{~kW}\end{array}$ \\
\hline $\begin{array}{l}\text { Refueling station } \\
\text { cost (\$) }\end{array}$ & \multicolumn{3}{|c|}{-} & \multicolumn{2}{|c|}{$\begin{array}{c}141,000 \text { per truck for } 10 \\
\text { fleet; } 43,000 \text { per truck for } \\
50 \text { fleet }\end{array}$} & 7,000 \\
\hline Tire (6 pieces/truck) & \multicolumn{6}{|c|}{ Michelin 215 75R17.5 } \\
\hline Capital cost (\$) & 75,000 & 75,000 & 115,000 & 105,000 & 145,000 & $\begin{array}{l}150,000- \\
180,000\end{array}$ \\
\hline $\begin{array}{l}\text { Battery pack } \\
\text { specific cost } \\
\text { (\$/kWh) }\end{array}$ & - & - & $\begin{array}{l}\text { See SI - } \\
\text { Section } 7\end{array}$ & - & - & $\begin{array}{l}\text { See SI- } \\
\text { Section } 7\end{array}$ \\
\hline $\begin{array}{l}\text { Maintenance cost } \\
\text { (\$/mile) }\end{array}$ & 0.2 & 0.2 & 0.16 & 0.22 & 0.22 & 0.14 \\
\hline
\end{tabular}

Vehicle and parts specifications: (Freightliner 2014; Kenworth 2014; Eaton 2014; SEV 2014; Allison Transmission 2015; Cummins 2015). Cost data sources: (Fairley 2011; Sankey et al. 2011; Deal 2012; ATRI 2013; ANL 2013; Lee et al. 2013, Gibson and Adamson 2013; WVU 2014).

EIO-LCA to analyze the energy efficiency, water use, and emissions from refueling station construction and operation (CMU GDI 2008), based on the parameters in Table 1 and the following section. Lee et al. (2013) used a similar method, combining process-based and EIO-LCA approaches, oftentimes called a hybrid LCA. 


\subsubsection{Cost}

We include purchase cost without incentives, maintenance and repairs cost, fuel cost, and additional internal combustion engine (ICE) emissions-related cost (e.g., aftertreatment fluid cost). We account for air emissions damage cost as mentioned earlier. All monetary values are in constant 2015 dollars. Purchase prices for model year 2015 class 6 freight trucks are $\$ 75,000, \$ 115,000$, and $\$ 105,000$ for diesel, hybrid, and CNG models, respectively (Deal 2012; ANL 2013). The electric truck with an 80 kWh battery costs $\$ 150,000$ and the one with a $120 \mathrm{kWh}$ battery costs $\$ 180,000$ (SEV 2014). Maintenance and repair costs are $\$ 0.2 /$ mile for diesel, 0.16 for hybrid, 0.22 for CNG, and 0.14 for electric (ANL 2013; ATRI 2013). For hybrid and electric trucks, we assume three battery replacements over a vehicle's operating lifetime. The first replacement will be covered by manufacturer warranty and the remaining two will cost fleet operators. Future battery price is expected to go down to $\$ 250 / \mathrm{kWh}$ by 2020 (Fairley 2011; Sankey et al. 2011; Gibson and Adamson 2013). A CNG refueling station costs about $\$ 141,000$ per truck for a fleet of 10 natural gas trucks and $\$ 43,000$ for a fleet of 50 trucks (WVU 2014). Electric vehicle supply equipment (EVSE) cost per truck is around $\$ 7,000$ (Lee et al. 2013). For current fuel prices, we use state-by-state monthly data (AAA 2015; EIA 2015a). We use fuel price data for pure biodiesel (B100) in 2015 (OPIS 2016; DOE 2016) and take a weighted energy-equivalent aggregation for B20 by the 20-80 volume share of biodiesel and petroleum diesel. For future fuel price evolution, we use EIA's three fuel price projections (baseline, high, and low) for petroleum diesel, CNG, and electricity (EIA 2015b). It has been reported that approximately two regenerations of a diesel particulate filter (DPF) are required per week totaling a half an hour of down time and an additional 0.4 gallon of fuel used per week (CARB 2008). Selective catalytic reduction (SCR) for NOx emission control consumes urea with approximately $3 \%$ of the diesel fuel gallon burnt, at a cost of $\$ 4 /$ gallon. A residual value is not included in our calculation, because our previous study (Lee et al. 2013) shows the residual value is not significant. We assume vehicle lifetime as $560,000 \mathrm{~km}$ (or 350,000 miles) (Huai et al., 2006) over a 20 -year time horizon (2015 - 2035). For overall (social) life cycle cost analysis, we take the following method:

$O L C C_{c, t}=T C O_{c, t}+\sum_{i=0}^{20} \frac{\left(S C C_{t, i} \cdot C E_{t, i}\right)+\left(A E D C_{c, t, i} \cdot A P E_{c, t, i}\right)}{(1+d)^{i}}$

where $O L C C_{c, t}$ and $\mathrm{TCO}_{c, t}$ refer to overall life cycle cost (OLCC) and total cost of ownership (TCO) (see Lee et al. 2013) for the $t$-th technology in $c$-th county in the continental U.S., respectively; $S C C_{t, i}$ and $C E_{t, i}$ are social cost of carbon (SCC) and carbon emissions (CE) for the $i$-th year and $t$-th technology, respectively; $A E D C_{c, t, i}$ and $A P E_{c, t, i}$ are air emissions damage cost (AEDC) and air pollutants emissions 
(APE) for the $i$-th year and $t$-th technology in $c$-th county, respectively; and $d$ is discount rate for the time value of money.

\subsubsection{Fuel Supply for Diesel, Biodiesel, and Natural Gas}

Upstream energy, water, and emissions factors associated with petroleum diesel, soybean-based biodiesel, and natural gas fuel production, transmission, and distribution were taken from the GREET model (ANL 2015). The GREET model assumes about $1 \%$ fugitive methane emissions for natural gas. We also consider a 5\% emissions case, based on the literature (Howarth et al. 2011; Schwietzke et al. 2014; Camuzeau et al. 2015). For biodiesel (B20), 20\% of tail-pipe carbon emissions from the fuel combustion is assumed to be biogenic. Owing to the carbon sequestration credit by feedstock plant, B20's net carbon emissions from fuel combustion is $20 \%$ lower than conventional diesel. Without the carbon sequestration credit, GREET estimates that B20 creates about 13\% higher direct fuel supply GHG intensity (17 gram $\mathrm{CO}_{2} \mathrm{e} / \mathrm{MJ}$ ) compared to petroleum diesel (15 gram $\left.\mathrm{CO}_{2} \mathrm{e} / \mathrm{MJ}\right)$. For land use change (LUC) impact of biodiesel feedstock, we assume GHG emissions of 6 gram $\mathrm{CO}_{2} \mathrm{e} / \mathrm{MJ}$ for $\mathrm{B} 20$, based on recent federal and state regulatory studies on soybean biodiesel (Federal Register 2010; CARB 2015). The indirect impacts (e.g., LUC) of biofuels are still-evolving issues that have been extensively debated in academia (Searchinger \& Heimlich 2008; Searchinger et al. 2008; Wang et al. 2011; Dunn et al. 2013; Elshout et al. 2015) and in the policy arena (Porter 2015; Tyner 2016; Aneja et al. 2016).

\subsubsection{Electric Grid (Average \& Marginal)}

We use GREET factors for power plant construction and operation as well as power generation fuel supply. For on-site energy consumption, water use, and air emissions in power plants, we use EPA's CEM hourly data and NEI database (EPA 2015b, 2015c). This enables us to account for heterogeneity in energy efficiency and air emissions of different power plants in different locations and times. We estimate water withdrawal and consumption factors for thermo-electric power plants based on EIA data (EIA 2015c) for 2013. We aggregate individual boiler-level data to cooling systems and power plants, with differentiation by fuel type, prime mover, water source type (e.g., surface, ground, fresh, saline, etc.), and cooling system type (e.g., once-through, recirculating, dry, hybrid, etc.) for each state.

We model state-by-state hourly power generation with a simplified load-filling approach. We take 8760hour power load profiles (FERC 2015) and fill with actual hourly fossil fuel generation data (EPA 2015b) and renewable power generation (NREL 2015; EIA 2015c). We then convert these generation results to consumption-based hourly electricity mix, based on the methodology proposed by Marriott and 
Matthews (2005) and inter-state electricity trade data (EIA 2015c), as follows:

$E_{G e n_{s, h}}=\frac{\sum_{f}^{N_{s, F}}\left(P_{s, h, f} \cdot E_{s, h, f}\right)}{\sum_{f}^{N_{s, F}} P_{s, h, f}}$

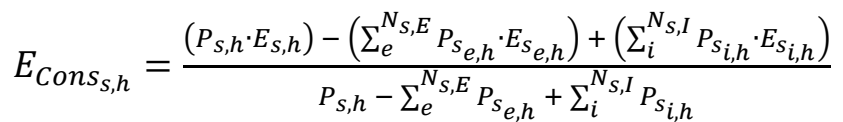

where $E_{G e n_{s, h}}$ and $E_{\text {Cons }_{s, h}}$ are energy use, water intensity, and air emissions factors for the $s$-th state and $h$-th hour for power generation and consumption, respectively; $P_{s, h, f}$ and $E_{s, h, f}$ are power generation and energy use, water intensity, and air emissions for the $s$-th state, $h$-th hour, and $f$-th fuel type; $P_{s_{e, h}}$ and $P_{s_{i, h}}$ are the export to the $e$-th state $\left(s_{e}\right)$ and the import from the $i$-th state $\left(s_{i}\right)$ in the $h$-th hour; and $N_{S, F}, N_{S, E}$, and $N_{S, I}$ are the total number of fuel types, exporters, and importers for the $s$-th state, respectively. Although the Eq. (3) and (4) are used for state-level results, whenever possible, we aggregate the input data based on individual boilers and/or generators.

Based on the same data sources and Siler-Evans et al.'s methodology (2012), we estimate hourly marginal electric grid efficiency, air emissions, and water consumption (see Figure 2 for example). This information constitutes average and marginal 8760-hour power consumption characteristics for 2014. For future years, we use state-by-state carbon emissions reduction goals in the clean power plan (CPP) (Federal Register 2015b). For this assessment, we divide all power generating units into three separate groups: zero emitting units (ZEU), U.S. Clean Power Plan (CPP) target units (CPPTU), and non-CPPTU. We estimate carbon emissions factors for 2030 as follows:

$C E F_{\text {Total,2014 }}=\frac{\mathrm{CO}_{2} \text { Total,2014 }}{G}$

$C E F_{\text {Total }, 2030}=\frac{1}{G} \cdot\left[G_{C P P T U} \cdot C E F_{C P P T U} \cdot(1-\alpha)+G_{\text {Non-CPPTU }} \cdot C E F_{\text {Non-CPPTU }}\right]$

$\gamma=\frac{C E F_{\text {Total,2030 }}}{C E F_{\text {Total,2014 }}}$

$E F_{L C, 2030}=E F_{\text {Infra }}+E F_{F S}+\left(\gamma \cdot E F_{G e n}\right)$

where $\mathrm{CO}_{2_{\text {Total,2014 }}}$ is total (direct and on-site) carbon dioxide emissions (kg); $G$ is total power generation (kWh); $C E F_{\text {Total,2014 }}$ and $C E F_{\text {Total,2030 }}$ are overall carbon emission factors for 2014 and 2030; $G_{C P P T U}, G_{N o n-C P P T U}, C E F_{C P P T U}$, and $C E F_{N o n-C P P T U}$ are power generation and carbon emissions factors for CPPTU and Non-CPPTU; $\alpha$ is the CPP carbon emissions reduction target; $E F_{L C, 2030}$ is life cycle 

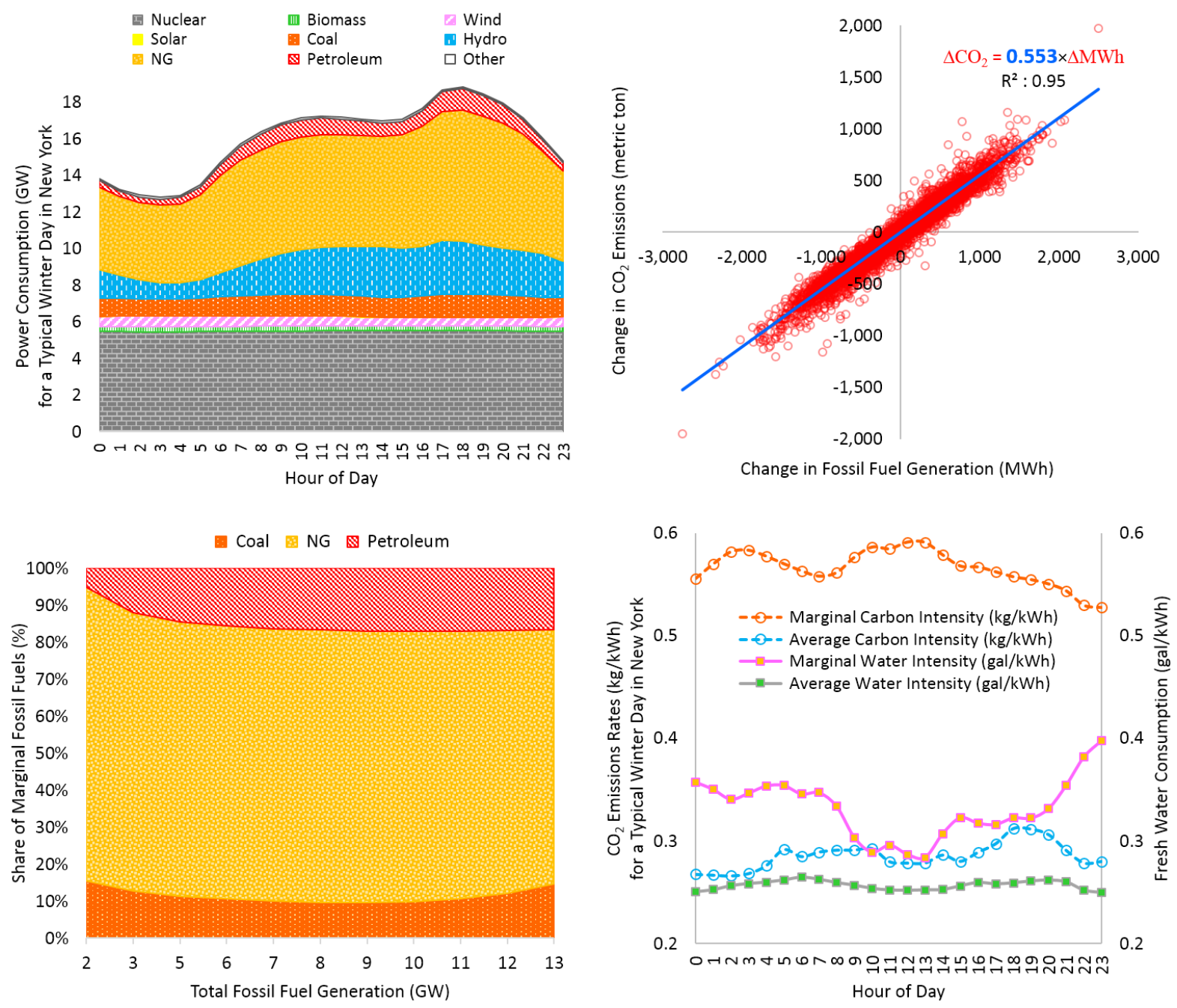

Figure 2. Example of hourly average and marginal emissions rates for the state of New York in winter in 2014. Power consumption fuel mix (top left); Marginal carbon dioxide emissions based on 8760hour (a whole year) marginal power consumption (top right); Relationship between marginal fossil fuel mix and total fossil fuel generation as a proxy of overall power demand (bottom left); Comparison between on-site (not life cycle) average and marginal hourly carbon dioxide emissions and fresh water consumption (bottom right). For a full data set, see SI-Section 3.

energy use and emissions factors for 2030; $E F_{I n f r a}, E F_{F S}$, and $E F_{G e n}$ are energy use and emissions factors for 2014 infrastructure, fuel supply, and generation (or on-site), respectively. Note that $C E F_{Z E U}$ is zero and thus not included in Eq. (6) and that the CPP carbon emissions reduction only applies to direct (or on-site) emissions in Eq. (8). Given the complexity of water consumption for power generation, carbon emissions reduction may not be directly related to water use reduction. For simplicity, however, we apply the same method above for water consumption for future years' power generation and consumption. Our effort of basing electric grid analysis on marginal factors aligns with 
the needs and transitions towards consequential LCA (Plevin et al. 2014; McManus \& Taylor 2015; Yang 2016). Further refinement for a complete consequential LCA would be needed. See SI - Section 3 for energy efficiency, water intensity, and air emissions factors for marginal power consumption.

\subsubsection{Vehicle Dynamic Simulation and Integration with VSP-based Emissions Model}

For vehicle operation energy consumption, we use ADVISOR (ImagineMade, 2014), a vehicle dynamic simulator. Compared to a simpler tractive energy-based model (Davis and Figliozzi, 2013; LaClair 2012), the vehicle dynamic simulation software accounts for non-linear behavior of vehicle components (e.g., non-constant efficiency of internal combustion engine, traction battery, etc.). Also, the vehicle dynamic simulator is helpful for reducing over- or under-estimation, as the software accounts for physical limits of vehicle performance including top speed, maximum payload, and drive cycle traceability. U.S. EPA specifically sets allowable range of traceability (following requested vehicle speed) (40 CFR part 1066). Based on this requirement, we filter simulation results and use only those that pass the traceability test. For the tail-pipe emissions analysis, we utilize MOVES (EPA 2014), a modal emissions model based on emissions data stratification by statistical or deductive definition of vehicle operating modes. MOVES is built upon the concept of vehicle specific power (VSP), the instantaneous tractive power per unit mass of the vehicle, proposed by Jimenez (1999). However, MOVES has some disadvantages. Examples include lack of transparency of input data, mismatch with real-world vehicle test results, time lag in data collection and implementation for more recent model years, no consideration of variations in vehicle specifications or physical capacity (e.g., traceability), etc. For CNG vehicles, MOVES provides emissions factors only for transit buses. We take the ratios between the emissions factors for diesel and CNG buses and apply them to diesel trucks and get CNG truck factors. Before doing so, as shown in Figure 3, we adjust CNG bus emissions factors based on vehicle test data (Yoon et al. 2013; WVU 2014) to reflect recent advances in CNG vehicles such as stoichiometric engine equipped with a three-way catalyst (TWC) system. MOVES also provides no emissions factors for hybrid vehicles. For hybrid and idle reduction technologies, we build our own map-based emissions modeling approach based on ADVISOR internal combustion engine model and MOVES emissions factors for conventional vehicles. More detailed description is provided in Supporting Information (SI) - Section 1. Figure 4 shows an example of our integrated vehicle dynamic and emissions simulations based on ADVISOR and MOVES. Following the hybrid-electric vehicle test guidelines proposed by Wayne et al. (2004) and to minimize bias, we make sure that the final state of charge (SOC) at the end of each drive cycle (e.g., 62.5\% in Figure 4) is the same as the initial SOC at the beginning of the drive cycle. 

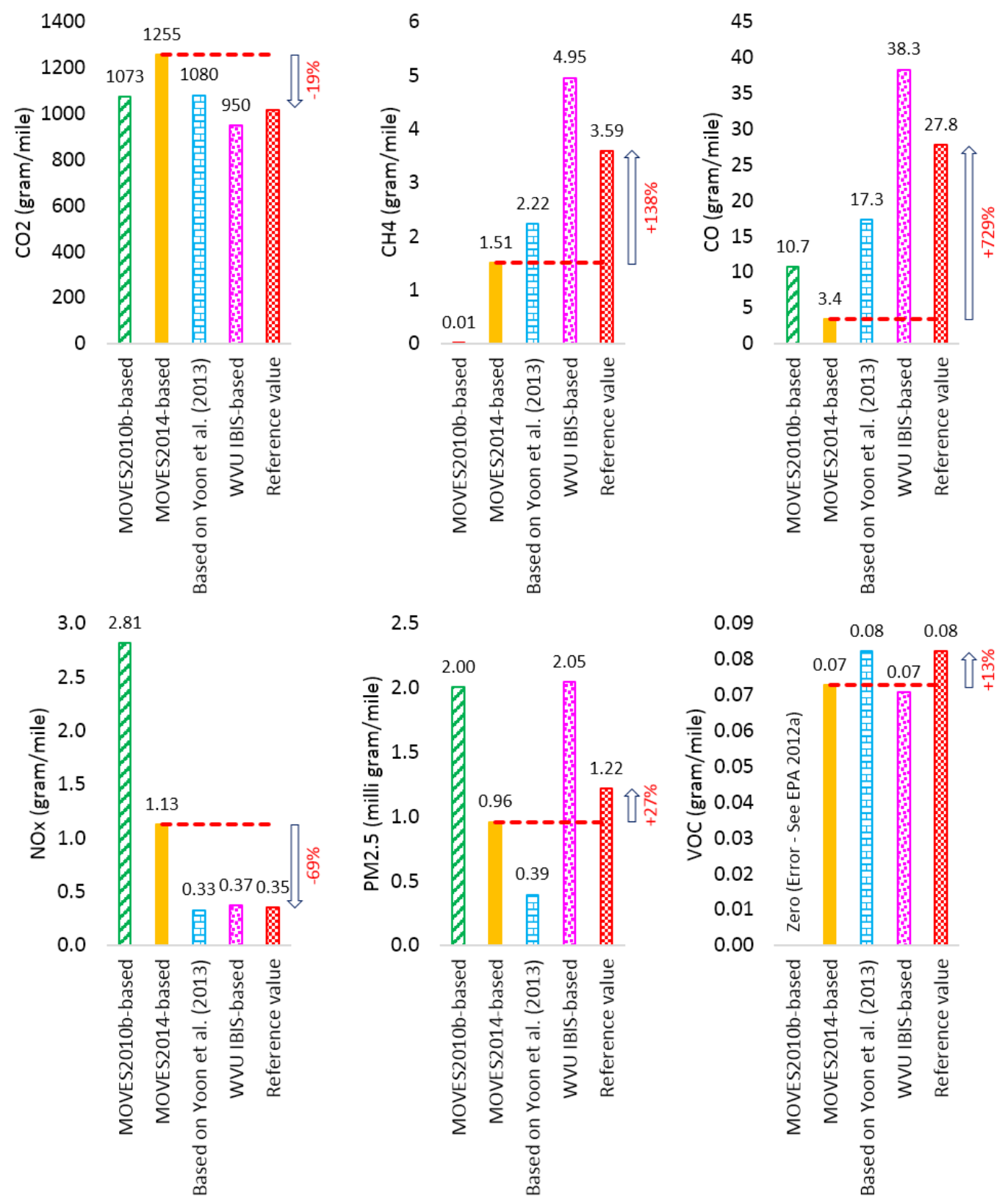

Figure 3. Adjustment factors for MOVES2014-based tail-pipe emissions rates for CNG medium-duty truck. Two sets of vehicle test data (Yoon et al. 2013; WVU 2014) for EPA Heavy-Duty Urban Dynamometer Driving Schedule (HD-UDDS) were used for reference (average of the two data sets). All test vehicles were equipped with stoichiometric engine and TWC aftertreatment system. For MOVES2010 erroneous data and bugs (e.g., zero VOC rates), see EPA materials (2012a, 2012b).

We use drive cycles from publicly-available data sources - the ARTEMIS project (ARTEMIS 2006), the NGSIM program (FHWA 2004), ADVISOR (ImagineMade 2014), MOVES (EPA 2014), and TSDC (NREL 2014). Although not all of the drive cycles collected are freight truck-specific and only some of them are real-world, they are still useful to build the spectra of possible driving conditions (Duran and Walkowicz 

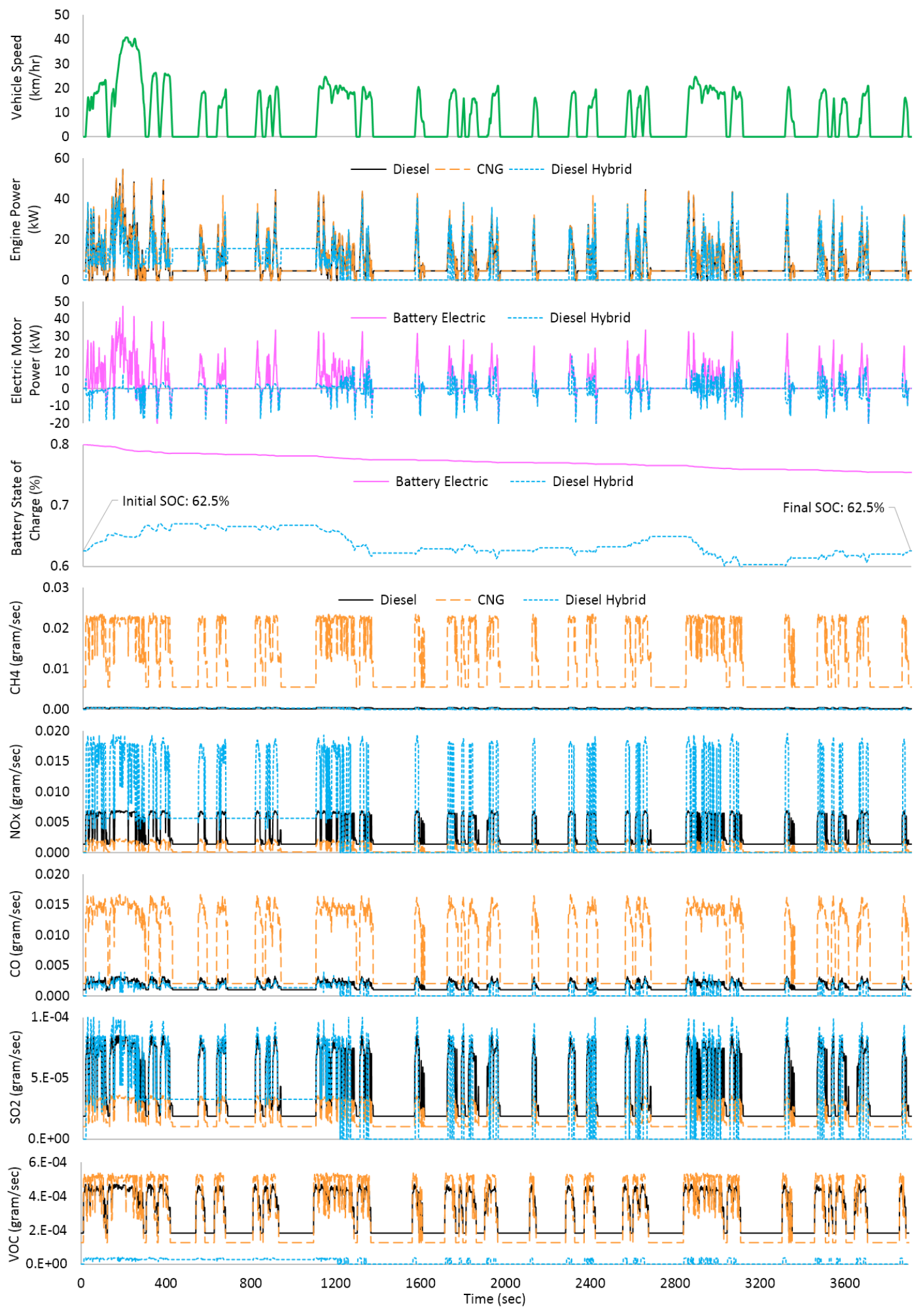

Figure 4. Vehicle dynamic and emissions simulation - example results for Hybrid Truck Users Forum Class 6 Parcel Delivery Driving Schedule (HTUF-6PDDS). 
2013). Energy consumption and emissions can be similar for completely different drive cycles, if they share common characteristics (Watson et al. 1983; EPA 1993; O'Keefe et al. 2007; Lascurain 2008; Clark et al. 2010; Lascurain et al. 2012; Burton et al. 2013a, 2013b; LaClair et al. 2014). These studies support our parametric approach for the prediction of energy use and emissions based on statistical parameterization of input conditions.

\subsubsection{Life Cycle Inventory Parameterization}

We aim to find parameterized causal relationships that can effectively bridge the time scale difference between physics simulation and LCA-based decision-making. For this, we first construct a sample space based on thousands runs of physics simulations described above. Part of the simulation results is shown in Figure 5, where each data point represents an aggregated result of an individual simulation illustrated in Figure 4 as an example. We then develop a statistical and causal relationship between input (transportation) and output (environmental impact) variables. From the "causal" relationship perspective, it is evident that vehicle operation for goods movement causes energy consumption and emissions. The challenge is then how to identify or parameterize the underlying relationship between the cause and effect. One of the variables that can effectively characterize the vehicle movement or transportation is average trip speed (the overall distance traveled per given time). As previous studies and our simulation results in Figure 5 indicate, there is a close relationship between average trip speed and direct vehicle operation energy use and emissions. However, the main reason that we pick average trip speed as a key input parameter lies in the very structure and characteristics of life cycle results from physics simulations. Figure 6 shows life cycle energy consumption, broken down into individual components, based on the vehicle dynamic simulations of light- and medium-duty vehicles. Note that the modeled light-duty vehicle is based on the Toyota Corolla. The electric grid we used for the results shown in Figure 6 is based on the U.S. national average for illustration; the overall relationship is also seen in other cases. The horizontal axes are different because of the differences in the top speeds of light- and medium-duty vehicles as well as electric and non-electric trucks.

In Figure 6, six things are worth mentioning. First, vehicle and parts production tends to be constant. Its relative impact is more significant for electric vehicles than for non-electric counterparts. Second, for non-electric vehicles, the ICE-associated energy use changes drastically over the average trip speed spectrum. Overall life cycle energy consumption is dominated by this ICE energy loss which varies the most with average trip speed. Third, the influence of other operation-related direct energy use components is relatively small for non-electric vehicles, regardless of vehicle types or weight classes. 

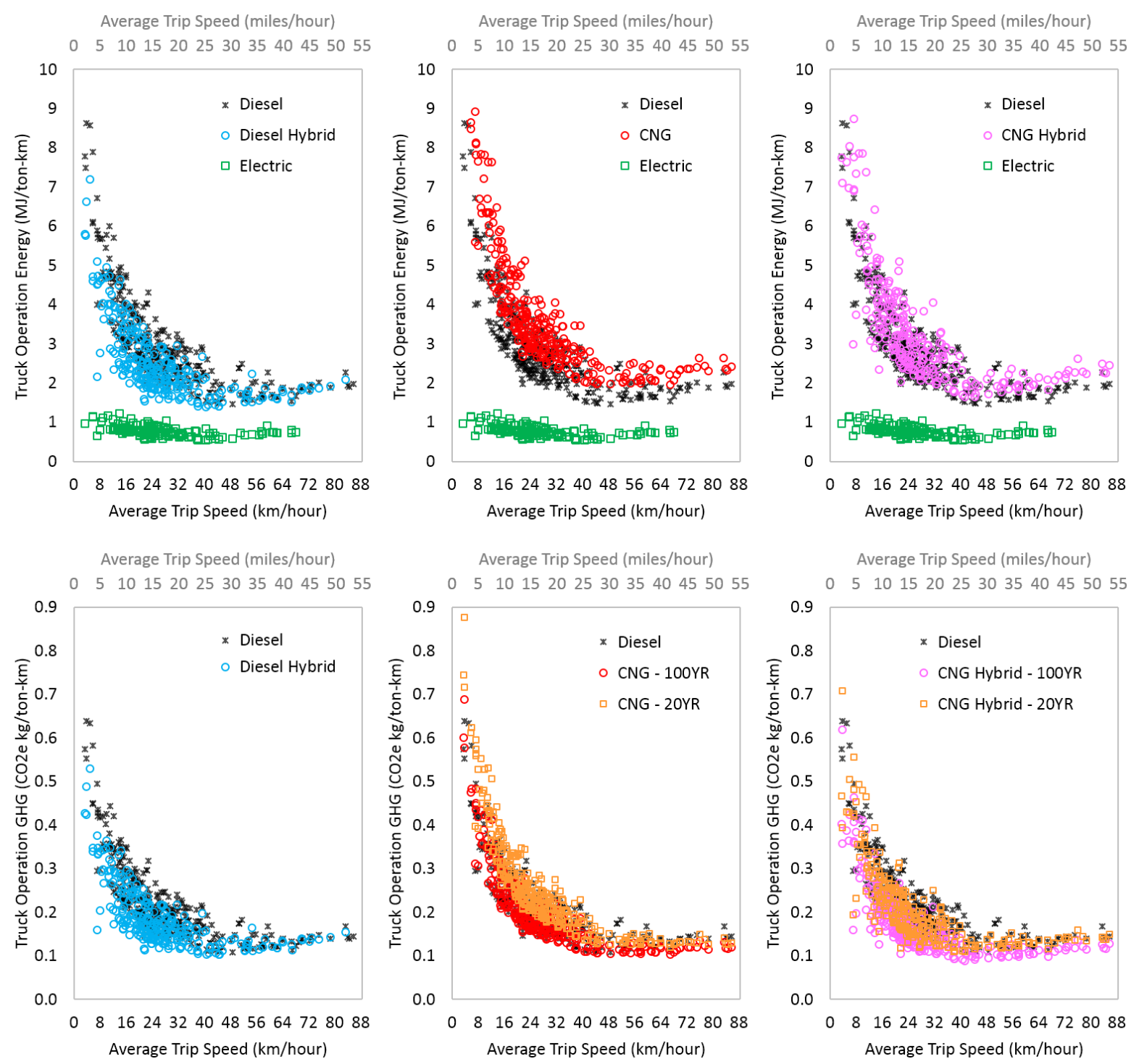

Figure 5. Use phase energy consumption and tail-pipe greenhouse gas emissions for medium-duty freight truck - moving a ton of payload per unit distance. Energy use for the electric truck refers to the input (purchased) utility AC electricity to Level $2 \mathrm{EVSE}$, that is, energy consumed by the external charger. CNG 20-YR and 100-YR refer to the time horizon of the global warming potential. Tail-pipe GHG emissions from the electric vehicle are not shown; see Figure 11 for life cycle emissions results.

Auxiliary load for freight trucks, unlike passenger transportation, is relatively small. In fact, some factors contribute to further enhancing the dependency on average trip. For instance, the increase of aerodynamic drag is roughly proportional to the square of average trip speed. Fourth, in the case of light-duty electric cars, electric motor energy loss and aerodynamic drag are more dominant than other components, which all vary with average trip speed. This is why we see average trip speed dependency in life cycle results of electric cars. Fifth, the energy use and emissions for upstream fuel supply is 


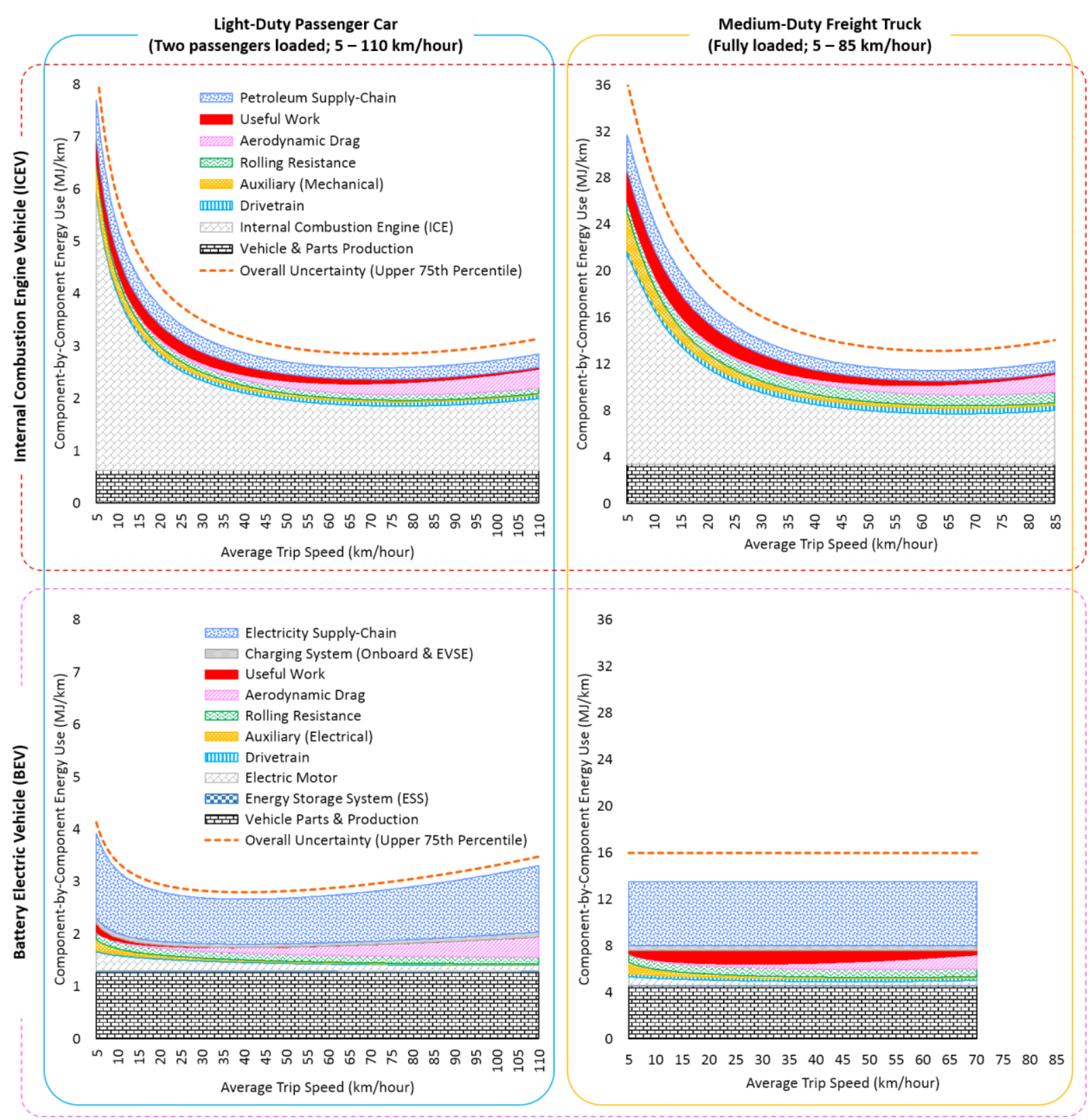

Figure 6. Parametric structure of life cycle energy consumption and its variation with different technologies (i.e., internal combustion engine vs. battery electric) and different vehicle weight classes and/or types (i.e., light-duty passenger cars vs. medium-duty freight trucks).

directly proportional to operation energy use. Since direct vehicle operation energy use has a close relationship with average trip speed, the same pattern will be observed in upstream fuel supply results. This in turn increases the dependency on average trip speed even more for aggregated life cycle results. Sixth, for electric trucks, neither operational nor life cycle energy shows a strong dependency on average trip speed, unlike non-electric trucks. Interestingly, this distinctly different pattern between electric and non-electric trucks is not observed in light-duty vehicles. Both electric and non-electric cars 
show average trip speed-dependent life cycle results. The unique energy consumption pattern of electric trucks calls for a different characterization parameter. For this, again, we rely on physics simulation as discussed below.

In general, for non-electric trucks, no matter what the propulsion technology (ICE or hybrid) or fuel type (diesel or CNG) is, energy use and emissions patterns depend on average trip speed. Despite its physical intuitiveness and transportation relevance, however, average trip speed alone cannot fully explain the changing behavior of vehicle energy consumption and emissions. Note that there are variations in Figures 5-6 that don't depend on average trip speed, whether direct operation or life cycle results. This is particularly true for electric trucks. For the same transportation efficiency or average trip speed, the results vary widely. According to our simulation, these variations are mostly due to useful work (or kinetic energy) that doesn't have a strong relationship with average trip speed. Therefore, another parameter is needed to capture the kinetic characteristics, in addition to the kinematic metric of average speed. To this end, we turn to the concept of positive kinetic energy (or PKE) (Watson et al. 1983) and define weighted PKE (WPKE in ton $\mathrm{m} / \mathrm{sec}^{2}$ ), as follows:

$W P K E=\frac{\sum_{i=0}^{T-1} m_{i}\left(V_{i+1}{ }^{2}-V_{i}{ }^{2}\right)}{\int_{0}^{T} V d t}$ for $V_{i+1}>V_{i}$

where $m_{i}$ and $V_{i}$ are vehicle weight (ton) and speed (m/sec) for the $i$-th moment (second) of total time duration $(T)$ of the given trip, and $V$ is vehicle speed at time $t$. The newly-defined WPKE can account for medium- and heavy-duty vehicles' dominant kinetic energy in total vehicle energy consumption as well as a mass change over the freight delivery route. WPKE can explain most of the remaining variations for the same average trip speed. And this has an important implication. To some extent, WPKE can be used as a proxy for the driving behavior impact with the average trip speed (or transportation efficiency) controlled. Put another way, WPKE can explain the variations observed for the same average trip speed, which is mostly related to driving behavior difference. The effectiveness of WPKE can be seen in Figure 7 as well as in $\mathrm{SI}$ - Section 10.

\subsubsection{Scaling Factors}

In addition to the kinematic (average trip speed) and kinetic (WPKE) parameters, we also account for factors that have overarching and universal effect on energy use and emissions but in a different way for each of the technologies. As can be seen in Figure 7, vehicle weight explains the gap between the two groups of results in the WPKE spectrum. The general principle is that increasing total weight causes 

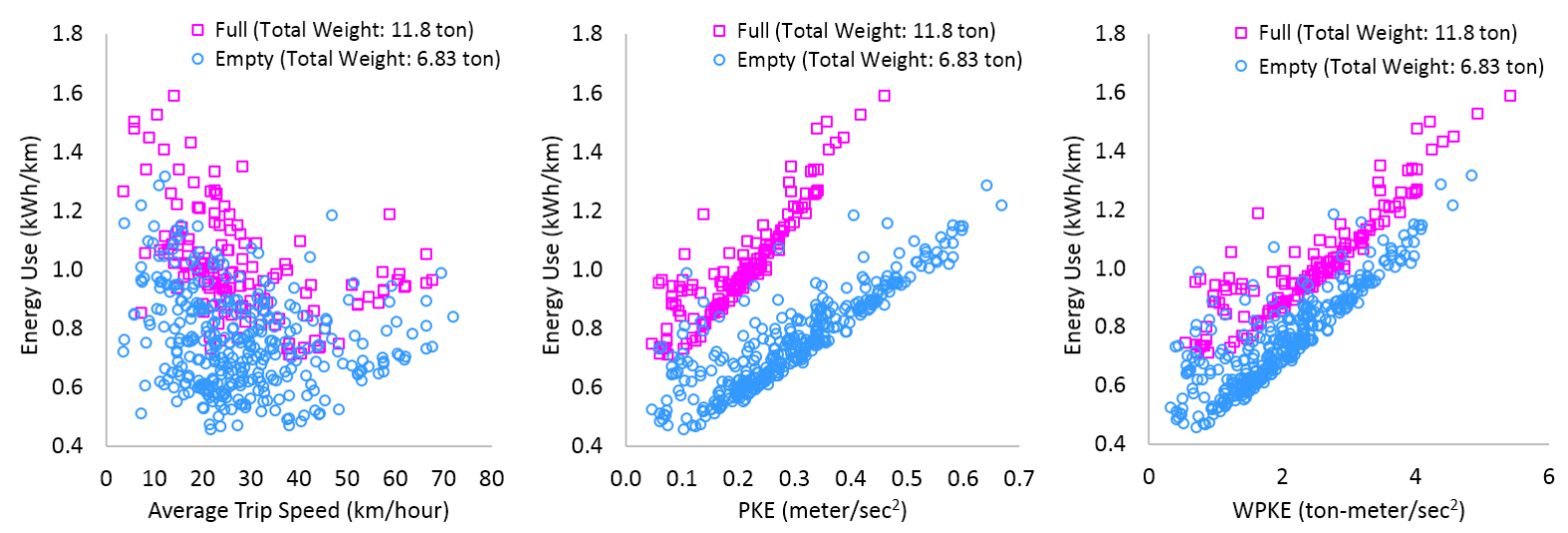

Figure 7. Relationship between energy use for electric truck operation and kinematic (i.e., average trip speed and PKE) and kinetic (e.g., WPKE) variables.

more energy consumption and emissions. On top of that, to incorporate the impact of spatial-temporal heterogeneity of climate and road grade, we develop scaling factors for parameterized analysis. Figure 8 shows an example of parametric scaling for climate condition variations, based on the electric vehicle test data as well as EPA MOVES and IBIS models (ANL 2014; EPA 2014; WVU 2014). This type of correction factor can also be found in sensitivity analyses - see Noel and Wayson (2012) for example. Interestingly enough, the scaling factors for climate condition variation show an asymmetric pattern, as do road grade impacts (see SI - Section 11). We use county-by-county hourly climate condition profiles and integrate them with the scaling factors, as shown in the example in Figure 8. Cold or hot climates increase energy consumption for both diesel and electric trucks, but non-electric trucks exhibit a different pattern from their electric counterpart. Non-electric trucks consume more energy for airconditioning while removing the engine's waste heat and overcoming the hot ambient temperature. In winter time, the energy consumption becomes lower, owing to the waste heat of the engine available for cabin heating, but can increase again as the climate condition becomes more extreme. However, climate condition does not always explain the overall impact, because of the confounding effect of fuel prices, specifically due to monthly fuel prices variations. As illustrated in Figure 8, diesel fuel prices decreased from 2014 to 2015, while CNG prices were relatively steady, and show a direct relationship with seasonal temperature variations. Electricity tends to be more expensive in summer than in winter. Therefore, in Los Angeles, with a mild winter, higher summer electricity prices have larger impact than climate conditions, leading to higher fueling cost in summer than in winter. This is not the case for the New York area, where a cold winter results in higher fuel costs in winter even though there are higher electricity rates during summer. 

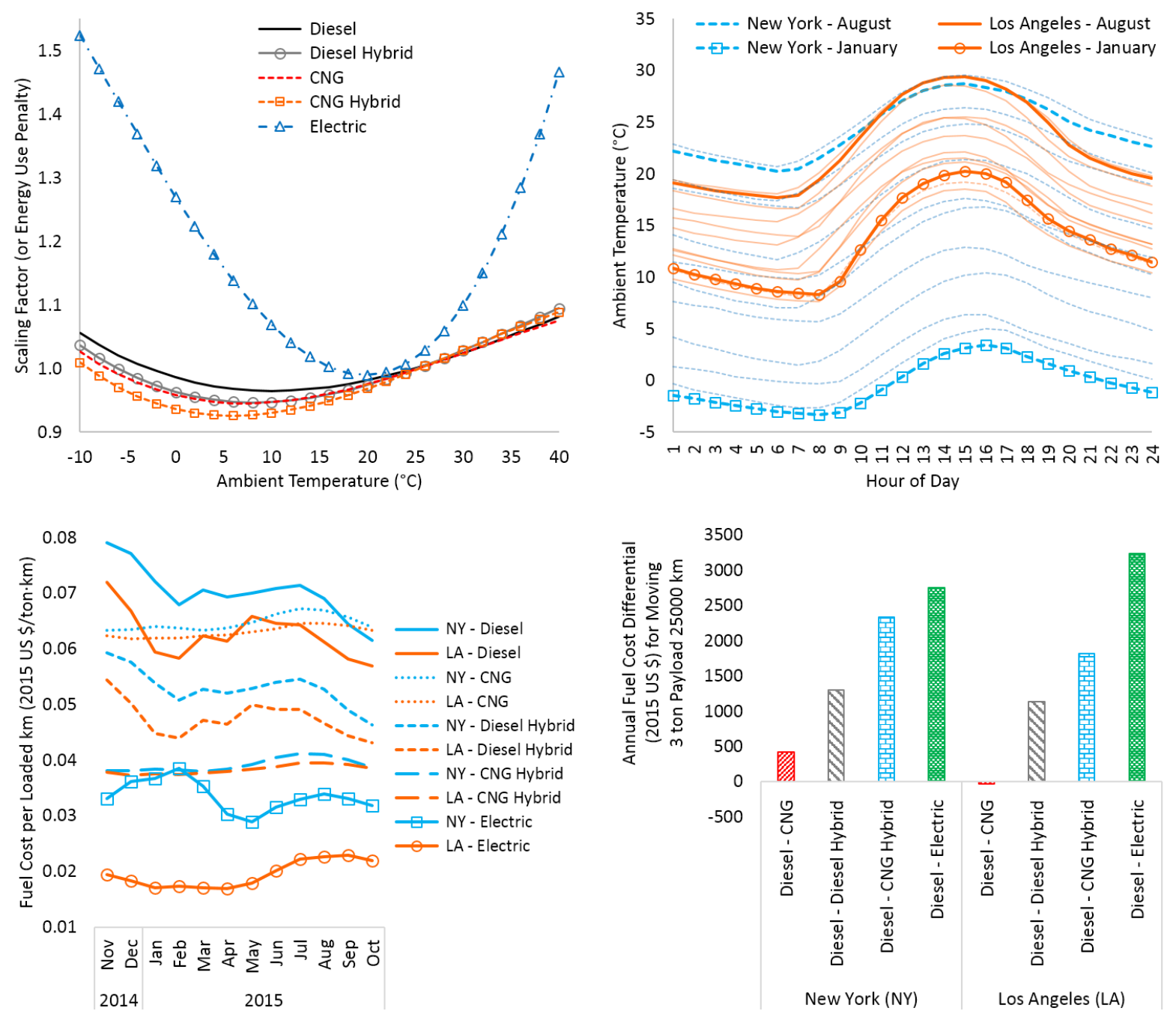

Figure 8. Impact of local climate condition and seasonal electricity prices variation. Scaling factor function for temperature variation (top left); Average hourly temperature profiles for 12 months in two select metropolitan areas - New York and Los Angeles (top right); Fuel cost with both temperature ( $6 \mathrm{am}-9 \mathrm{pm}$ average) effect and monthly fuel prices variations accounted for (bottom left); Annual fuel cost differential relative to conventional diesel trucks (bottom right).

The characterization variables discussed in detail thus far are independent variables of the parametric LCA model in Eq. (1). To deal with non-linearity of life cycle results in the average trip speed spectrum, we also use inverse, log, and square of average trip speed. We adopt multiple linear regression principles in estimating the coefficients in Eq. (1). To comply with the linearity assumption, we take a log-log transformation of both sides of the equation, which is why Eq. (1) is in the product of powers. We present the results visualized over the entire spectrum of average trip speed (as a proxy for transportation efficiency). For demonstration, we integrate our model with the 1,520 samples of medium-duty truck activity records across the U.S. from the National Renewable Energy Laboratory's 


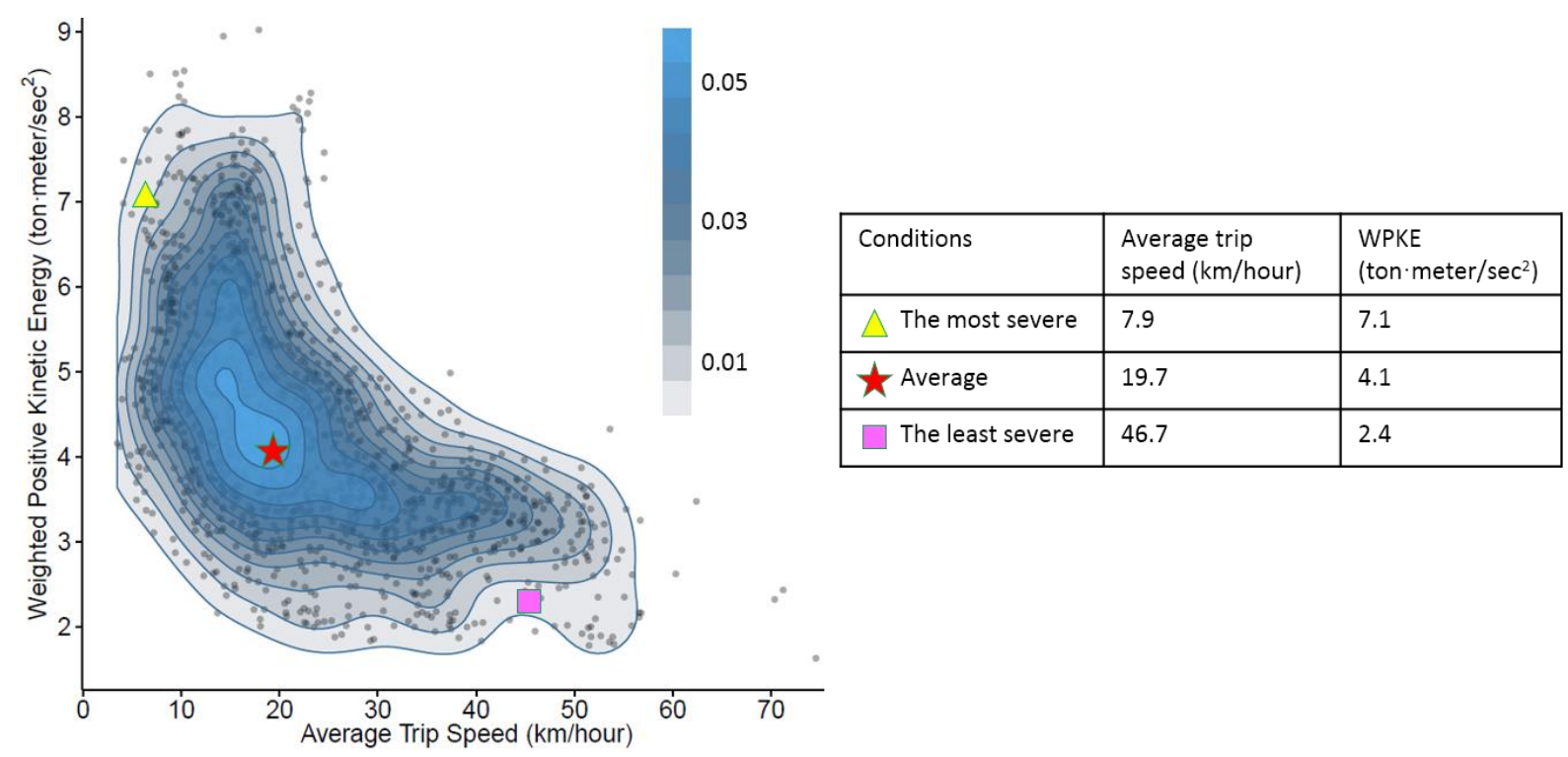

Figure 9. Probability density for statistical operating condition of medium-duty freight trucks adapted based on the data from the NREL Fleet DNA project (1,527 samples) and EPA SmartWay program. The most severe, average, and the least severe conditions refer to the combinations of 5-, 50-, and 95-th percentiles in the two-dimensional probability density domain. For commonly-used drive cycles' average trip (or drive cycle) speed and statistics (e.g., average trip speed and positive kinetic energy), please see Figure S8 in SI Section 9.

Fleet DNA project data (Walkowicz et al. 2014) (Figure 9). The data are based on vehicle routes and duty cycle characterization parameters, which matches the parametric modeling framework. We also incorporate EPA SmartWay data (EPA 2015d) for statistical distribution of vehicle weight and real-world electric truck charging profiles (Duran et al. 2014).

\section{Results}

\subsection{Parametric Prediction of Life Cycle Inventory and Impact Assessment Results}

The life cycle inventory results for vehicle and parts production are shown in Figure 10. Despite the lighter curb weight and lack of diesel engine, bulky multi-speed transmission, and after-treatment systems, the electric truck is generally worse than the other technologies, mostly because of the battery packs.

Tables 2 and 3 show linear regression-based parametric models for life cycle energy use and greenhouse gas emissions, respectively. For electric trucks, we only show the two select U.S. states for simplicity, for minimum and maximum cases as of 2015 in the U.S. These predictive models explain 91 to $98 \%$ of the 
variability of life cycle results. Other parametric LCA models can be found in the SI. Figure 11 is a graphical illustration of the predictive models in the average trip speed domain, for a half-loaded vehicle weight with average PKE (Figure 9). Because of electric trucks' low dependence on average trip speed,

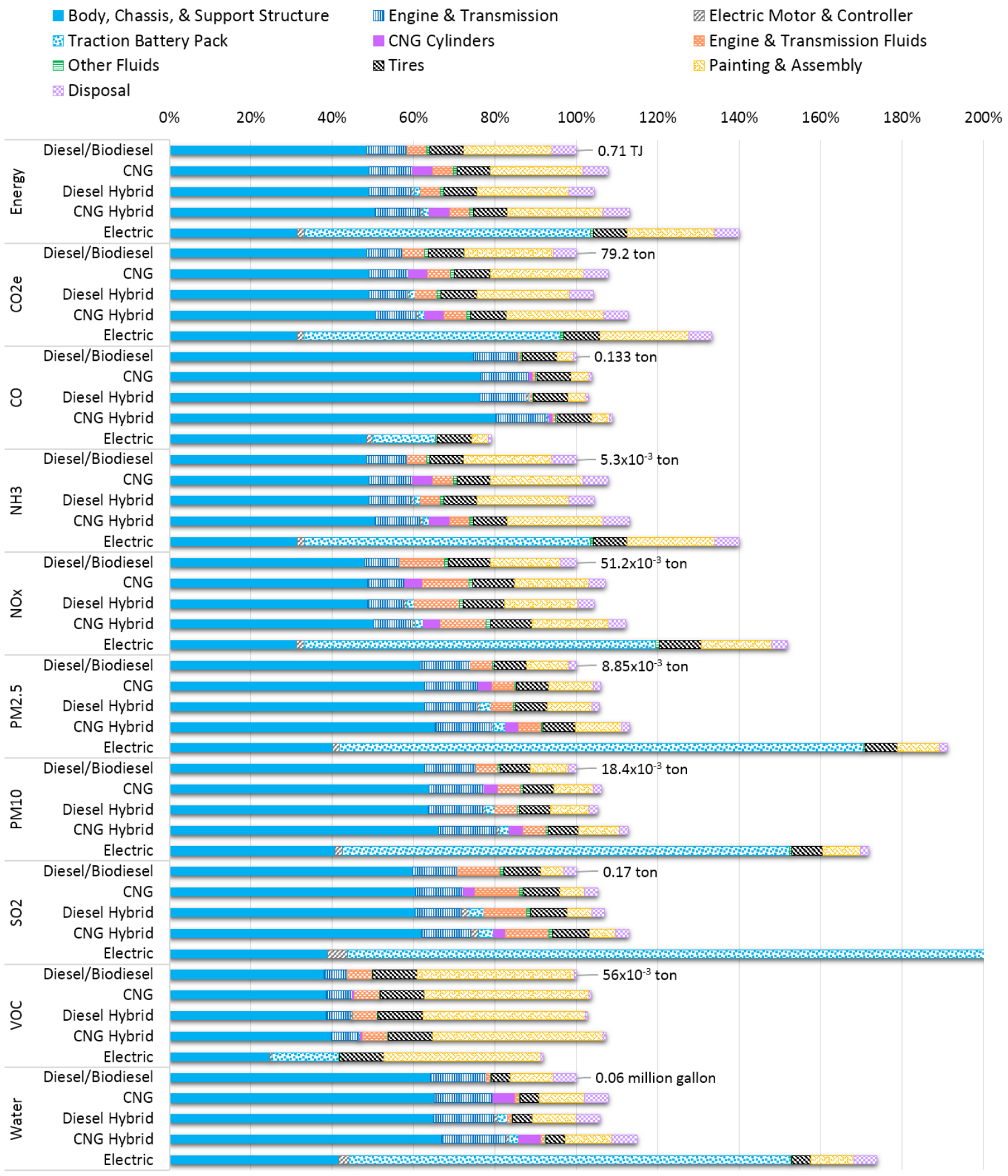

Figure 10. Medium-duty freight truck and parts production inventory (per truck and for truck lifetime) in percentage with the diesel truck as reference (100\%). Detailed data are provided in SI. 
we show constant reference values for electric trucks. The minimum for electric trucks is the daytime charging case for the state with the least value for each impact category, whereas maximum is the nighttime charging case for the state with the largest values.

As shown in Figure 11, CNG trucks show the highest life cycle energy consumption across the board.

Although CNG trucks have lower tail-pipe GHG emissions than their diesel counterpart, CNG trucks emit

Table 2. Life cycle inventory ( $\mathrm{LCl}$ ) prediction model for energy consumption - see Supporting Information for normalized regression model and AIC-based linear regression result for energy use as well as and other life cycle inventory and impact prediction models.

\begin{tabular}{|c|c|c|c|c|c|c|c|c|}
\hline \multirow{5}{*}{ Predictors } & \multicolumn{8}{|c|}{ Dependent variable: $\hat{Y}$, Life cycle energy use $(\mathrm{MJ} / \mathrm{km})$ per truck } \\
\hline & \multicolumn{8}{|c|}{$\log (\hat{Y})=\hat{\beta}_{0}+\hat{\beta}_{1} m_{p}+\hat{\beta}_{2} W P K E+\hat{\beta}_{3} \bar{V}_{\text {trip }}+\hat{\beta}_{4} \bar{V}_{\text {trip }}{ }^{-1}+\hat{\beta}_{5} \log \left(\bar{V}_{\text {trip }}\right)+\hat{\beta}_{6} \bar{V}_{\text {trip }}{ }^{2}$} \\
\hline & \multicolumn{3}{|c|}{ Conventional ICE } & \multicolumn{3}{|c|}{ Hybrid Electric } & \multicolumn{2}{|c|}{ Battery Electric } \\
\hline & Diesel & B20 & CNG & Diesel & B20 & CNG & CA & CT \\
\hline & \multicolumn{8}{|c|}{ Coefficients $\hat{\beta}_{i}$ and t-statistic (in parenthesis) } \\
\hline Intercept & 2.39 & 2.43 & 3.58 & 1.721 & 1.76 & 3.34 & 1.55 & 1.84 \\
\hline merceps & $(119)$ & $(120)$ & $(62.4)$ & $(173)$ & $(175)$ & $(83.7)$ & $(193)$ & (209) \\
\hline$m_{p}$ & $\begin{array}{r}1.35 \times 10^{-2} \\
(12.9)\end{array}$ & $\begin{array}{r}1.36 \times 10^{-2} \\
(12.9)\end{array}$ & $\begin{array}{r}1.29 \times 10^{-2} \\
(12.6)\end{array}$ & $\begin{array}{r}1.81 \times 10^{-2} \\
(10.8)\end{array}$ & $\begin{array}{r}1.82 \times 10^{-2} \\
(10.8)\end{array}$ & $\begin{array}{r}3.67 \times 10^{-2} \\
(17.04)\end{array}$ & $\begin{array}{r}3.06 \times 10^{-2} \\
(31.1)\end{array}$ & $\begin{array}{r}3.31 \times 10^{-2} \\
(30.7)\end{array}$ \\
\hline$W P K E$ & $\begin{array}{r}0.1198 \\
(66)\end{array}$ & $\begin{array}{r}0.12 \\
(65.8)\end{array}$ & $\begin{array}{r}0.108 \\
(58)\end{array}$ & $\begin{array}{r}0.155 \\
(55)\end{array}$ & $\begin{array}{l}0.155 \\
(54.8)\end{array}$ & $\begin{array}{l}0.123 \\
(34.6)\end{array}$ & $\begin{array}{l}0.192 \\
(66.9)\end{array}$ & $\begin{array}{l}0.207 \\
(66.2)\end{array}$ \\
\hline $\bar{V}_{\text {trip }}$ & $\begin{array}{r}-1.62 \times 10^{-2} \\
(-21.8) \\
\end{array}$ & $\begin{array}{r}-1.63 \times 10^{-2} \\
(-21.8) \\
\end{array}$ & & & & & & \\
\hline $\bar{V}_{\text {trip }}{ }^{-1}$ & $\begin{array}{l}3.28 \\
(30) \\
\end{array}$ & $\begin{array}{l}3.28 \\
(30) \\
\end{array}$ & $\begin{array}{r}1.73 \\
(9.95) \\
\end{array}$ & $\begin{array}{r}3.95 \\
(38.5) \\
\end{array}$ & $\begin{array}{r}3.96 \\
(38.4) \\
\end{array}$ & & & \\
\hline $\log \left(\bar{V}_{\text {trip }}\right)$ & & & $\begin{array}{r}-0.4 \\
(-25.3) \\
\end{array}$ & & & $\begin{array}{r}-0.4 \\
(-34) \\
\end{array}$ & & \\
\hline $\bar{V}_{\text {trip }}{ }^{2}$ & $\begin{array}{r}1.59 \times 10^{-4} \\
(21.5) \\
\end{array}$ & $\begin{array}{r}1.6 \times 10^{-4} \\
(21.5) \\
\end{array}$ & $\begin{array}{r}7.14 \times 10^{-5} \\
(22.5) \\
\end{array}$ & $\begin{array}{r}3.76 \times 10^{-5} \\
(13.3) \\
\end{array}$ & $\begin{array}{r}3.77 \times 10^{-5} \\
(13.2) \\
\end{array}$ & $\begin{array}{r}9.37 \times 10^{-5} \\
(22.4) \\
\end{array}$ & $\begin{array}{r}7.64 \times 10^{-5} \\
(28.6) \\
\end{array}$ & $\begin{array}{r}8.33 \times 10^{-5} \\
(28.5) \\
\end{array}$ \\
\hline Adj. $R^{2}$ & 0.97 & 0.97 & 0.98 & 0.94 & 0.94 & 0.91 & 0.94 & 0.93 \\
\hline F-stat. & 5424 & 5397 & 6383 & 2444 & 2435 & 1685 & 2349 & 2297 \\
\hline$N_{\text {obs }}$ & 725 & 725 & 680 & 624 & 624 & 643 & 489 & 489 \\
\hline
\end{tabular}

$m$ : total vehicle weight (metric ton) $=$ sum of curb weight $m_{c}$ (metric ton) and payload $m_{p}$ (metric ton), $\bar{V}_{\text {trip }}$ : average trip speed $(\mathrm{km} /$ hour $)=$ total distance traveled divided by total trip time taken, WPKE: $(m \cdot P K E)$ weighted positive kinetic energy (ton. meter $\left./ \mathrm{sec}^{2}\right)$, and $N_{\text {obs }}$ : the number of observations (or samples).

For battery electric, we here show the results for two select cases - minimum (daytime charging in California (CA) and nighttime charging in Connecticut (CT), based on consumption-based marginal electric grid. Other states fall between the two (minimum and maximum).

On top of this generic prediction equation, correction factors may be applied (multiplied) for temperature (Figure 8) and/or road grade (Figure S11). 
Table 3. Life cycle inventory ( $\mathrm{LCl}$ ) prediction model for GHG emissions (with 100-year horizon) - see Supporting Information for normalized regression model and AIC-based linear regression result for GHG emissions as well as other life cycle inventory and impact prediction models.

\begin{tabular}{|c|c|c|c|c|c|c|c|c|}
\hline \multirow{5}{*}{ Predictors } & \multicolumn{8}{|c|}{ Dependent variable: $\hat{Y}$, Life cycle GHG-100YR emissions (gram/km) per truck } \\
\hline & \multicolumn{8}{|c|}{$\log (\hat{Y})=\hat{\beta}_{0}+\hat{\beta}_{1} m_{p}+\hat{\beta}_{2} W P K E+\hat{\beta}_{3} \bar{V}_{\text {trip }}+\hat{\beta}_{4} \bar{V}_{\text {trip }}{ }^{-1}+\hat{\beta}_{5} \log \left(\bar{V}_{\text {trip }}\right)+\hat{\beta}_{6} \bar{V}_{\text {trip }}{ }^{2}$} \\
\hline & \multicolumn{3}{|c|}{ Conventional ICE } & \multicolumn{3}{|c|}{ Hybrid Electric } & \multicolumn{2}{|c|}{ Battery Electric } \\
\hline & Diesel & B20 & CNG & Diesel & B20 & CNG & VT & ND \\
\hline & \multicolumn{8}{|c|}{ Coefficients $\hat{\beta}_{i}$ and t-statistic (in parenthesis) } \\
\hline & 6.69 & 6.61 & 7.82 & 6.01 & 5.94 & 7.45 & 4.83 & 6.2 \\
\hline Intercept & (331) & (331) & (151) & (598) & (600) & (191) & (4055) & (678) \\
\hline$m_{p}$ & $\begin{array}{r}1.36 \times 10^{-2} \\
(12.9)\end{array}$ & $\begin{array}{r}1.35 \times 10^{-2} \\
(12.9)\end{array}$ & $\begin{array}{r}1.28 \times 10^{-2} \\
(13.9)\end{array}$ & $\begin{array}{r}1.83 \times 10^{-2} \\
(10.8)\end{array}$ & $\begin{array}{r}1.81 \times 10^{-2} \\
(10.8)\end{array}$ & $\begin{array}{r}3.57 \times 10^{-2} \\
(17.02)\end{array}$ & $\begin{array}{r}4.75 \times 10^{-3} \\
(32.5)\end{array}$ & $\begin{array}{r}3.4 \times 10^{-2} \\
(30.5)\end{array}$ \\
\hline$W P K E$ & $\begin{array}{r}0.12 \\
(65.6)\end{array}$ & $\begin{array}{l}0.12 \\
(66)\end{array}$ & $\begin{array}{r}0.1 \\
(59.1)\end{array}$ & $\begin{array}{l}0.156 \\
(54.8)\end{array}$ & $\begin{array}{r}0.154 \\
(55)\end{array}$ & $\begin{array}{r}0.12 \\
(34.8)\end{array}$ & $\begin{array}{r}0.0292 \\
(68.6)\end{array}$ & $\begin{array}{r}0.214 \\
(66)\end{array}$ \\
\hline $\bar{V}_{t r i p}$ & $\begin{array}{r}-1.64 \times 10^{-2} \\
(-21.9)\end{array}$ & $\begin{array}{r}-1.62 \times 10^{-2} \\
(-21.9)\end{array}$ & & & & & & \\
\hline $\bar{V}_{\text {trip }}{ }^{-1}$ & $\begin{array}{l}3.28 \\
(30)\end{array}$ & $\begin{array}{l}3.28 \\
(30)\end{array}$ & $\begin{array}{r}1.62 \\
(10.3) \\
\end{array}$ & $\begin{array}{r}3.97 \\
(38.4) \\
\end{array}$ & $\begin{array}{r}3.94 \\
(38.6)\end{array}$ & & & \\
\hline $\log \left(\bar{V}_{\text {trip }}\right)$ & & & $\begin{array}{r}-4.1 \\
(-28.8) \\
\end{array}$ & & & $\begin{array}{r}-0.38 \\
(-33.3)\end{array}$ & & \\
\hline $\bar{V}_{\text {trip }}{ }^{2}$ & $\begin{array}{r}1.6 \times 10^{-4} \\
(21.6) \\
\end{array}$ & $\begin{array}{r}1.59 \times 10^{-4} \\
(21.6) \\
\end{array}$ & $\begin{array}{r}6.31 \times 10^{-5} \\
(22) \\
\end{array}$ & $\begin{array}{r}3.77 \times 10^{-5} \\
(13.2) \\
\end{array}$ & $\begin{array}{r}3.75 \times 10^{-5} \\
(13.3) \\
\end{array}$ & $\begin{array}{r}8.87 \times 10^{-5} \\
(21.9) \\
\end{array}$ & $\begin{array}{r}1.1 \times 10^{-5} \\
(28.1) \\
\end{array}$ & $\begin{array}{r}8.63 \times 10^{-5} \\
(28.4) \\
\end{array}$ \\
\hline Adj. $R^{2}$ & 0.97 & 0.97 & 0.98 & 0.94 & 0.94 & 0.91 & 0.94 & 0.93 \\
\hline F-stat. & 5409 & 5460 & 7813 & 2434 & 2452 & 1669 & 2509 & 2274 \\
\hline$N_{o b s}$ & 725 & 725 & 680 & 624 & 624 & 643 & 489 & 489 \\
\hline
\end{tabular}

$m$ : total vehicle weight (metric ton) $=$ sum of curb weight $m_{c}$ (metric ton) and payload $m_{p}$ (metric ton), $\bar{V}_{\text {trip }}$ : average trip speed (km/hour) = total distance traveled divided by total trip time taken, $W P K E:(m \cdot P K E)$ weighted positive kinetic energy (ton. meter $\left./ \mathrm{sec}^{2}\right)$, and $N_{o b s}$ : the number of observations (or samples).

For battery electric, we here show the results for two select cases - minimum (daytime charging in Vermont (VT) and nighttime charging in North Dakota (ND), based on consumption-based marginal electric grid. Other states fall between the two (minimum and maximum).

On top of this generic prediction equation, correction factors may be applied (multiplied) for temperature (Figure 8 ) and/or road grade (Figure S11).

more GHGs for fuel supply-chain, vehicle and parts production, and infrastructure installation, which leads to very similar overall GHG emissions to that of diesel trucks in the case of $1 \%$ fugitive methane emissions. However, in the $5 \%$ fugitive methane emissions case, CNG trucks, whether conventional or hybrid, are the most carbon-intensive technologies in terms of both 100-and 20-year global warming potential impacts. Nevertheless, CNG trucks provide life cycle benefits over diesel trucks for water use, 

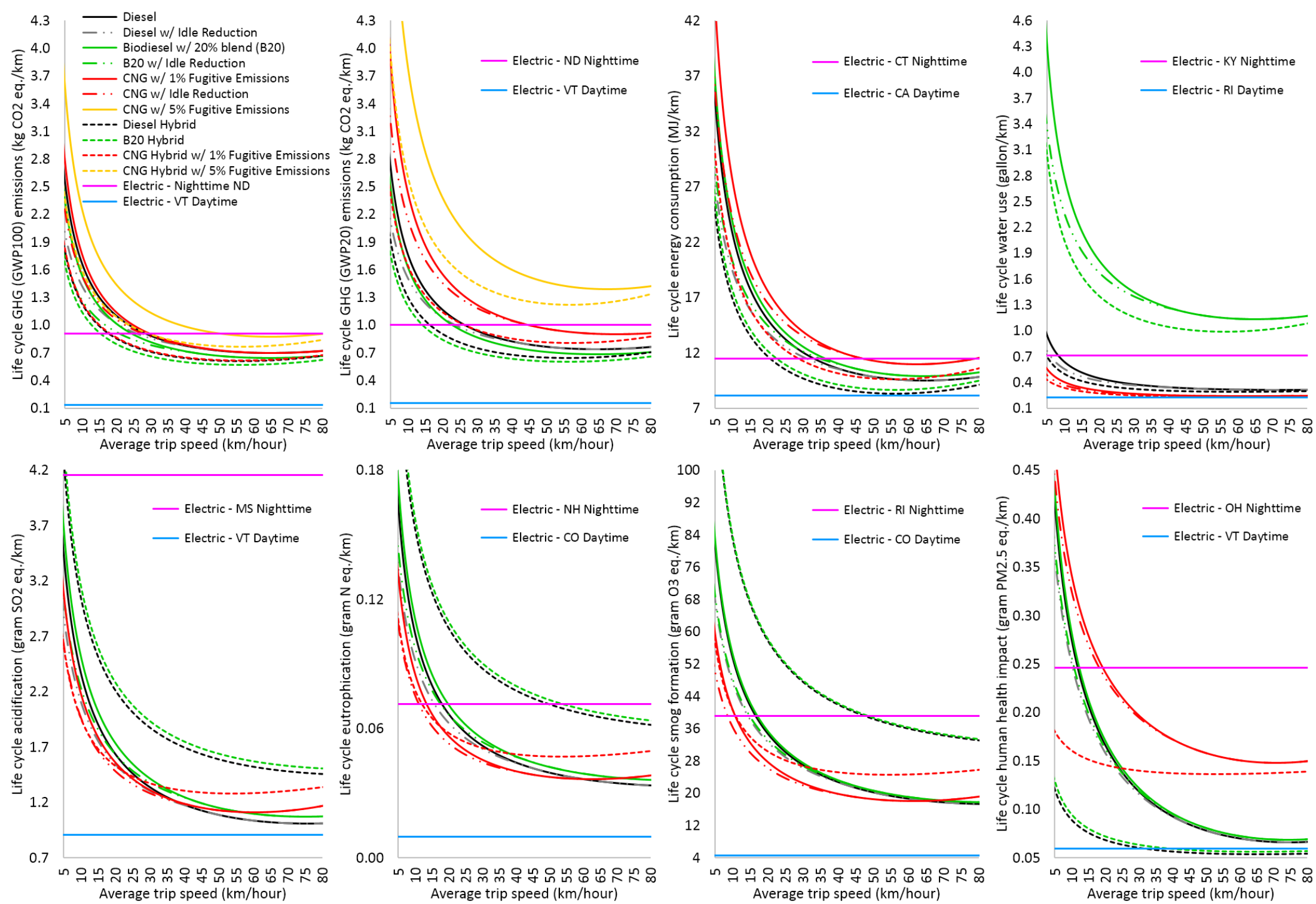

Figure 11. Parametric prediction of life cycle impact assessment (LCIA) results. Electric for two states with minimum and maximum values. 
acidification, eutrophication, and smog (ground-level ozone) formation impacts. Hybrid-electric technology emits much higher tail-pipe NOx (Figure 4) than conventional ICE trucks and thus has the largest impacts for acidification, eutrophication, and smog formation. Biodiesel (B20) trucks consume far more water than the other technologies. Electric trucks generally consume more (fresh) water than diesel or CNG trucks. Other than water use, electric trucks' overall life cycle environmental impacts are similar to or slightly higher than those of diesel trucks. Electric and hybrid (diesel and biodiesel) trucks are the most efficient and least GHG-emitting in general. As Lee et al. (2013) showed, the more severe the drive cycle is (Figure 9), the higher the advantage of electrification becomes. The same tendency can be found for idle reduction technologies.

\subsection{Carbon-Water Nexus and State-by-State Results}

We show state-by-state results in Figure 12 for two extreme cases - the most and least severe operating conditions (Figure 9). The most severe condition refers to the $95^{\text {th }}$ percentile of average trip speed and $5^{\text {th }}$ percentile of WPKE (Figure 9), and the least refers to the combination of $5^{\text {th }}$ and $95^{\text {th }}$ percentiles of average trip speed and WPKE, respectively. The operating condition severity is directly related to the overall energy intensity. As opposed to the constant values in Figure 11, now as we account for WPKE in addition to average trip speed, we have more accurate life cycle results for electric trucks, as shown in Tables 2 and 3. We present only conventional diesel and diesel-powered hybrid trucks as reference technologies to compare with electric trucks, because CNG and other non-electric truck technologies emit similar or higher GHGs, although CNG shows lower life cycle water-intensity (Figure 11). In many U.S. states, whether the most or least severe conditions, electric trucks provide GHG emissions reduction benefits, although electric trucks almost always consume more fresh water than dieselpowered technologies over the life cycle. Considering the results in Figure 12 are based on marginal nighttime electric grid, which tends to have higher carbon-intensity than average or daytime electric grid, we can say that the GHG emissions reduction benefits are robust.

Another thing to note in Figure 12 is the complexity of carbon-water intensity of thermo-electric power generation and resulting trade-offs of electric trucks. Simply put, the state emitting the least amount of GHGs is not necessarily the place where water intensity is the lowest. Nuclear generating units don't emit direct greenhouse gases, but depending on cooling system type and water source type, fresh water consumption can vary widely. For example, plant Vogtle in Georgia draws fresh water from the Savannah River for its recirculating cooling system, consuming 0.8 gallons of fresh water per $\mathrm{kWh}$ of electricity generated. Plant St. Lucie in Florida is also a nuclear power plant, but it draws saline water 

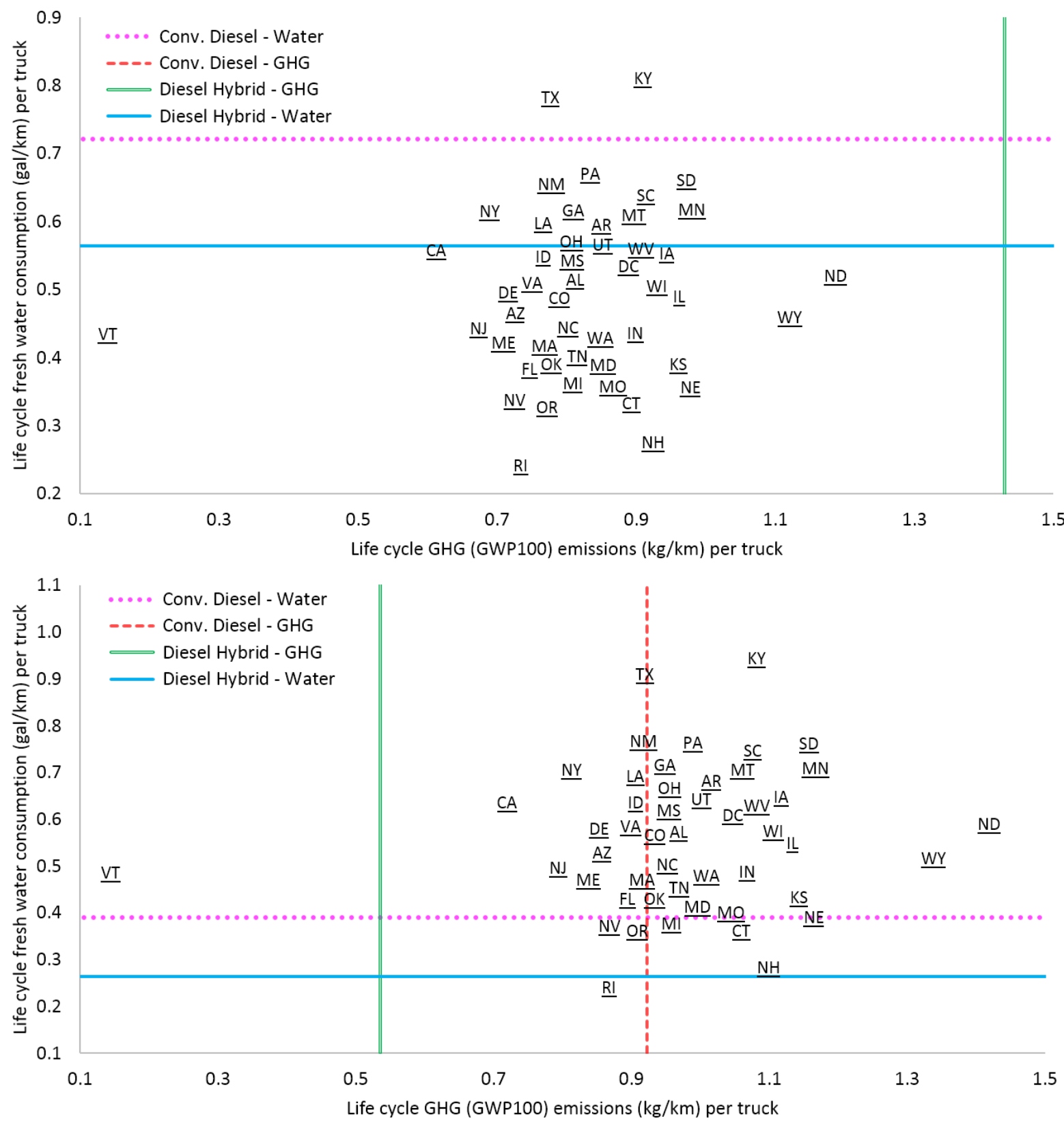

Figure 12. Life cycle greenhouse gas (GWP100) emissions and fresh water consumption comparison between electric (marginal electric grid and nighttime charging) and two select non-electric (conventional diesel and hybrid-electric diesel) technologies - for the most severe operating condition (top) and for the least severe (bottom), based on the Fleet DNA truck operation statistics (see Fig. 10).

from the Atlantic Ocean for its once-through cooling system, consuming 0 gallons of fresh water. In other words, despite their lower carbon-intensity advantage, nuclear power plants can add to regional water stress. In contrast, coal power plants do emit greenhouse gas emissions, but there are wide variations of water-intensity. For example, the coal power plant Bowen in Georgia draws fresh water 
from the Etowah River for its four recirculating cooling systems, consuming 0.4 gallons of fresh water on average per kWh of electricity generated. However, the coal power plant C R Huntley in New York draws fresh water from Niagara River for its once-through cooling system, with substantially lower fresh water consumption.

\subsection{The Impact of Air Emissions Damage Cost}

Based on both direct total cost of ownership, TCO, and indirect cost (i.e., monetized air emissions damage) - see Eq. (2), we look at three cases in the average trip speed and PKE domain (Figure 9) - the most severe, average, and the least severe conditions. As mentioned above, the most severe conditions favor electric trucks, confirming Lee et al.'s (2013) findings. We find that electric trucks are not costeffective in average and least severe operating conditions. For those conditions, conventional diesel with idle reduction (often called micro-hybrid) or diesel hybrid-electric are the most cost-effective, mostly owing to low diesel fuel prices as of 2015. For this reason, in Figure 13, we show only the results for the most severe condition, based on Monte Carlo simulations with a range of cost parameters (see SI Section 7). The results are based on nighttime charging and marginal electric grid. The overall cost (OLCC) difference between average and marginal electric grid cases, mostly owing to air emissions damage differential, ranges from $1-5 \%$. Based on the $O L C C_{c, t}$, we pick the most cost-effective truck technology in each county. If we exclude the idle reduction option, the truck technology choice is petroleum diesel hybrid or battery electric. Even under the low diesel fuel price condition, for severe operating conditions, battery electric trucks provide robust and positive net social benefits in many areas. Once we include the idle reduction option, however, $35 \%$ of the counties that favored electric trucks and $100 \%$ of the counties that favored diesel hybrid trucks will now favor idle reduction as the most cost-effective technology. This shows the disruptive effect of idle reduction technology, particularly for hybrid and electric trucks. This finding is in part due to the operating condition tested (the most severe) for which idle reduction can have the largest benefit (see Figure 11). For average and least severe operating conditions, petroleum diesel with idle reduction and diesel hybrid provide the largest net social benefit, respectively. Despite higher NOx emissions (Figure 4) and corresponding environmental impacts (Figure 11), higher fuel efficiency and lower GHG emissions benefits result in lower OLCC for hybrid trucks. All things considered, internalizing monetized air emissions damage doesn't make a big difference in comparing different truck technologies. 

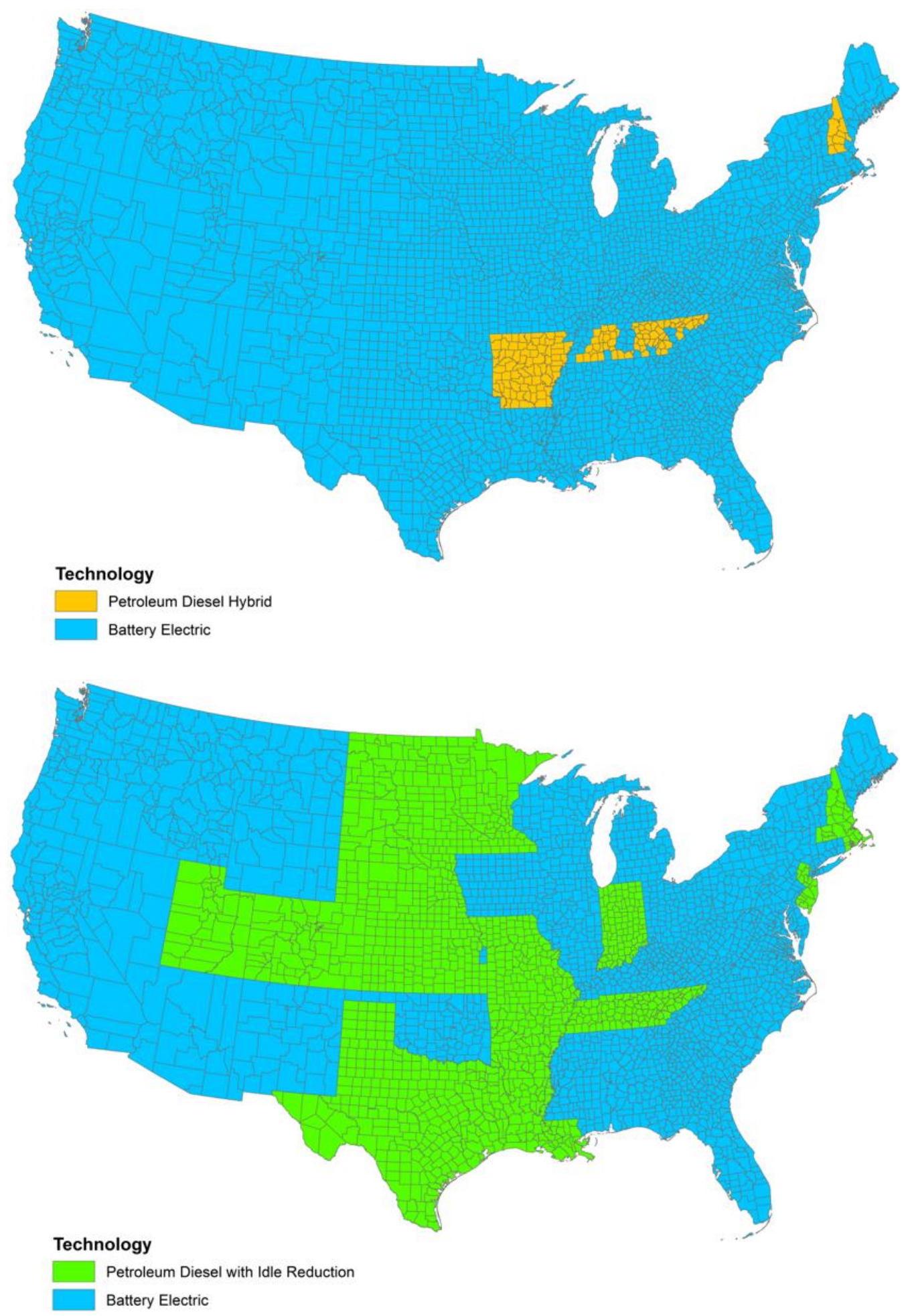

Figure 13. Spatial analysis of 2015 overall life cycle cost (sum of total cost ownership and monetized life cycle air emissions impacts) for most severe truck operating condition (see Figure 10) - the best application (or sweet spot) for electric trucks - excluding (top) and including (bottom) the idle reduction option, based on Monte Carlo simulation using real-world truck activity data. 


\subsection{Necessary Conditions for Robust Benefits from Truck Electrification}

The future is hard to predict. Nevertheless, successful medium-duty truck electrification requires electric trucks to be able to compete cost-effectively in major freight truck applications with typical or average operating conditions beyond the niche market. Using Monte Carlo simulations based on the cost analysis and the predictive LCA models above, we sweep through entire domain of average trip speed and WPKE in Figure 9 and identify conditions necessary for electric trucks to become cost-effective. In doing so, we simultaneously vary key input cost parameters (e.g., capital cost, fuel prices, etc.). A niche application for electric trucks is defined as the $5^{\text {th }}$ percentile in the cost-effectiveness probability domain, and major market or application refers to $50^{\text {th }}$ percentile in the same domain.

Figure 14 shows necessary conditions for electric trucks to be robustly cost-effective against petroleum diesel with idle reduction technology. Maximum break-even capital cost of electric trucks ranges from $\$ 170,000$ to $\$ 180,000$ for niche market and from $\$ 105,000$ to $\$ 130,000$ for major market. This confirms that electric trucks are cost-competitive and robust for niche market, even under 2015 electric truck prices $(\$ 150,000$ - $\$ 180,000$ for the largest and heaviest model - see Table 1$)$. However, to penetrate the major market, electric truck capital costs must fall by about half or $30 \%$ at least, varying by region. In terms of fuel prices, it is required that 2015-2030 average diesel fuel prices are no lower than 2-2.5 \$/gallon for the cost-effectiveness of electric trucks to be robust in the niche market application. This required range is lower than the 2015 average price in all the states, which means current low diesel fuel prices do not negate the cost-effectiveness of electrification in niche applications. However, more drastic conditions are needed for major market application robustness, that is, $6.5-8 \$$ /gallon. This result implies that within reasonably expected diesel fuel prices in the future, electric trucks' do not have cost-effective major market adoption potential. Even if credits are given to carbon emissions reduction for electric trucks, the SCC must be higher than $\$ 300-2,000 \$ /$ metric ton of $\mathrm{CO}_{2}$ to be robust in the major truck market. This is significantly higher than the typically-used SCC of $\$ 30-60$. Although not shown, according to our calculations, the maximum discount rate required ranges from $14 \%$ to $19 \%$ for the niche market, which is similar to or higher than the range of $5 \%-15 \%$ that is typically used, meaning that the cost-effectiveness of electric trucks in the niche market is robust. However, there exist no positive discount rate solutions for major market application, confirming that electric trucks are less likely to be cost-effective in the major market. This result can be inferred by the fact that the necessary maximum capital cost for major market (Figure 14-a) is below the normal range for an electric truck (\$0.15-0.18 million dollars). The electric trucks' robust cost-effectiveness for niche application is 
conditional on the expected payback time ranging from $11-20$ years. If the desired payback time is less than 10 years, it is very unlikely that an electric truck can be cost-competitive in comparison with non-

(a) Maximum electric truck purchase cost (2015 \$ in million)

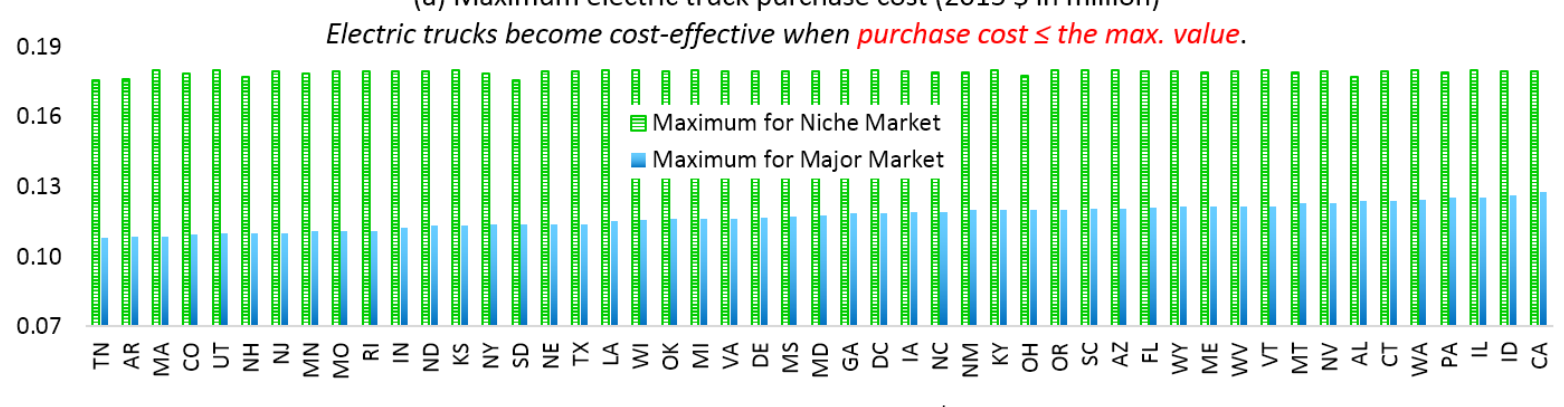

(b) Minimum diesel fuel price (2015 \$ per gallon)

Electric trucks become cost-effective when diesel price $\geq$ the min. value.
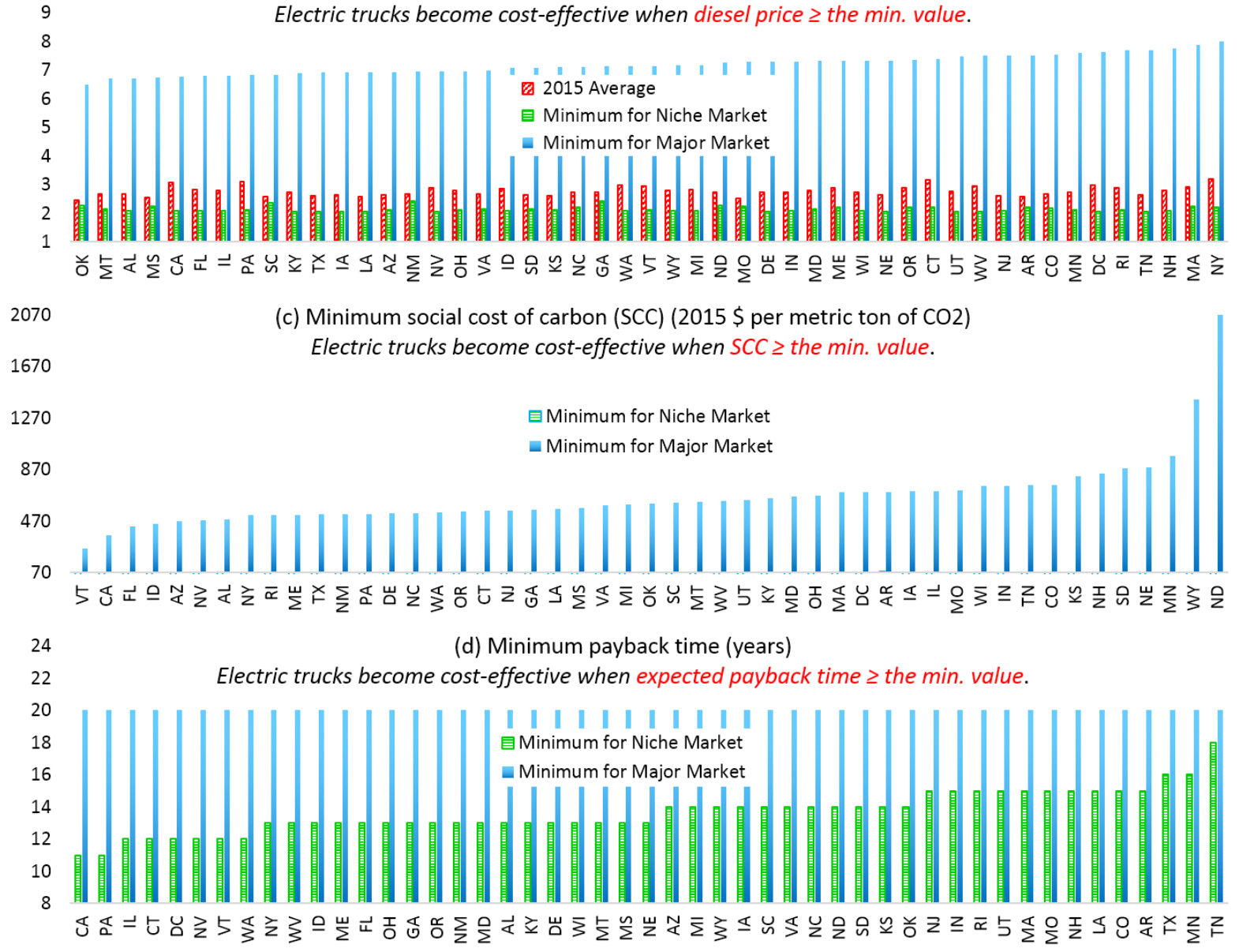

Figure 14. Necessary conditions for electrifying medium-duty freight trucks to be cost-effective, and for the advantage to be robust for a niche and major market penetration: (a) maximum electric truck capital cost; (b) minimum diesel fuel price; (c) minimum carbon price; (d) minimum payback time. Missing values in (c) indicate that electric trucks are cost-effective even without giving credits with social cost carbon. The analysis is based on Monte Carlo simulation using the parametric life cycle model, hourly temperature profiles, hourly marginal electricity consumption characteristics, statistical distribution of operating conditions (Figure 9). 
electric trucks. Lastly, given the wide range of variability of necessary conditions between regions, our analysis shows that policy incentives to promote electric trucks could be region-specific. For example, if electric trucks are to be adopted for a major market application in Massachusetts, about $\$ 40,000-$ $\$ 70,000$ incentives or tax credits for electric truck purchases may be needed to compensate the expensive upfront capital cost, whereas $\$ 20,000-\$ 50,000$ would be required in California.

\subsection{Impact of Average vs. Marginal Factors for Electric Grid}

Using marginal electric grid factors results in larger environmental impacts than when average factors are used (Figure 15). For example, electric trucks' GHG emissions reduction benefits over diesel trucks are $65 \%$ for average factors but $56 \%$ for marginal factors, on average. For areas with already high average carbon intensity factors, the GHG emissions reduction change is minimal - see the almost identical $90^{\text {th }}$ percentile values for GHG in Figure 15. In general, marginal vs. average electricity factors don't create critical difference in life cycle results, particularly for OLCC. Also, we find no meaningfully different life cycle results of using marginal factors to compare daytime vs. nighttime electric grid. Part of the reason is that seasonal variations are far more influential than daily (daytime vs. nighttime) variations in electric grid and the environmental impacts thereof.

\subsection{Impact of Driving Behavior}

Improved driving behavior (less aggressive driving for the same average trip speed) can reduce environmental impacts and cost (see all negative PCl's in Figure 15), regardless of technology. Recall that average trip speed is a proxy of transportation efficiency (see Section 2.2.6). The magnitude and sensitivity vary with technologies as well as environmental impact indicators, although the comparative results (e.g., Figure 13) remain the same. As shown in Figure 15, compared to diesel, behavioral change for electric trucks provides relatively larger GHG benefits but smaller cost benefits. Also, electric trucks show wider variations in the impact because of geographical heterogeneity in electric grid characteristics.

\section{Conclusion and Discussion}

Based on detailed physics simulations and statistical analysis, we developed parameterized economic and environmental LCA models for medium-duty freight truck technologies. In comparison with conventional LCA approaches, our parametric modeling approach improves predictive and descriptive power. 


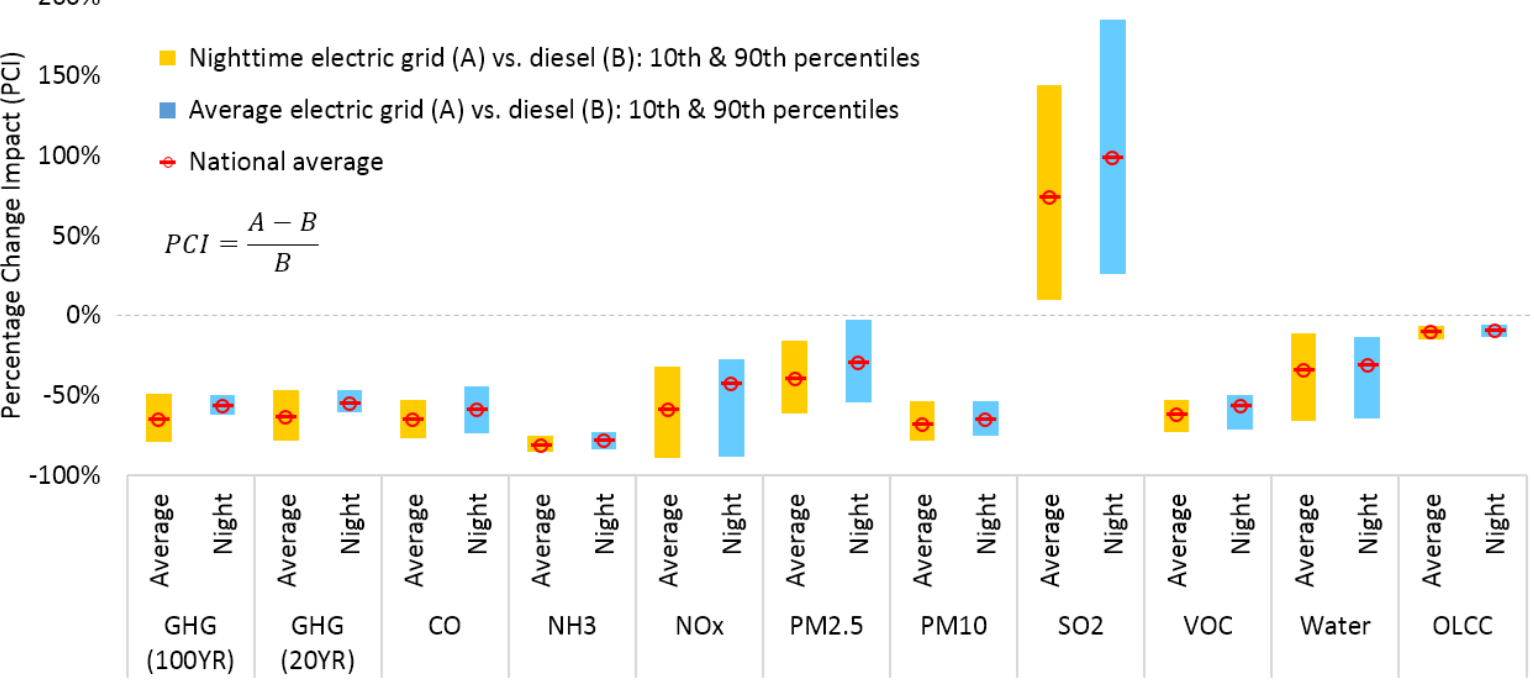

(b) Driving Behavior Change: \% Change Impact on LC Results

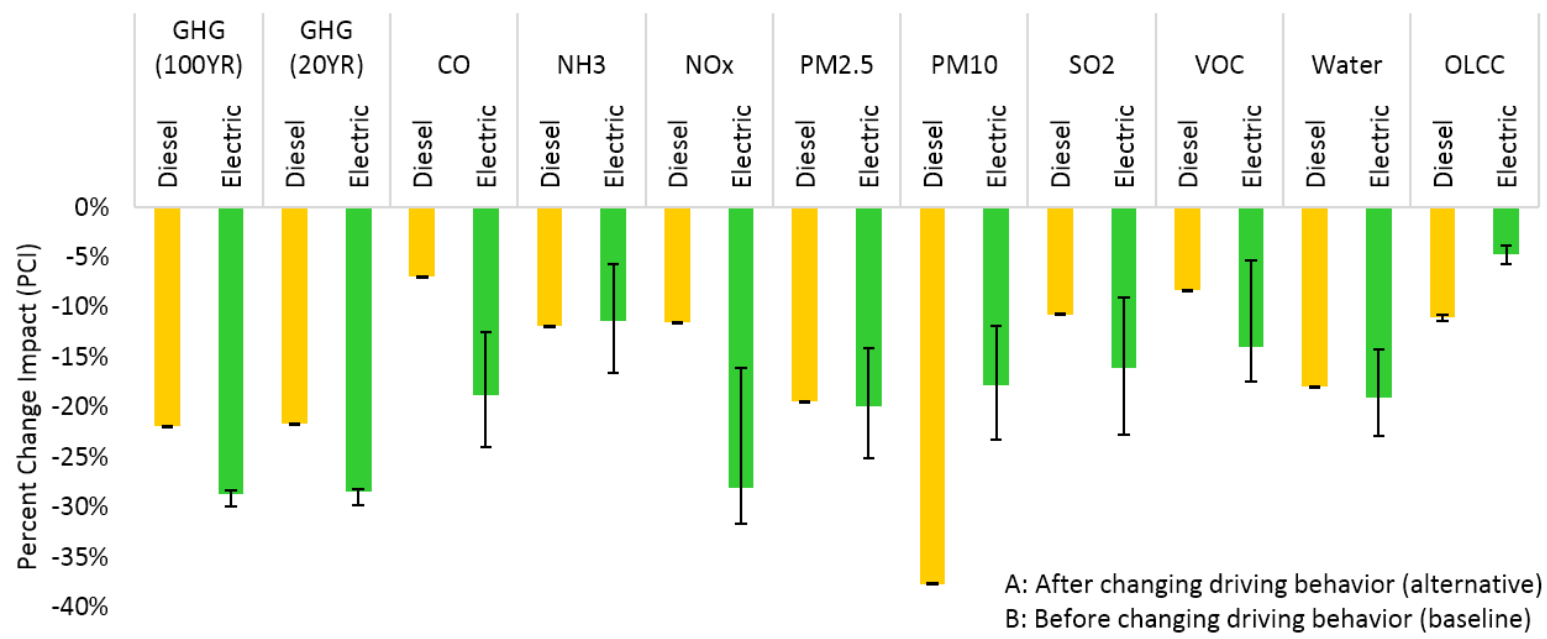

Figure 15. Percentage change impact ( $\mathrm{PCl})$ : (a) average and marginal electric grid vs. petroleum diesel for niche application condition, (b) after vs. before changing behavior to less aggressive driving for average operating condition. Error bars indicate geographical variations $\left(10^{\text {th }}\right.$ and $90^{\text {th }}$ percentiles in the continental U.S.) for each case considered. Negative PCI means savings or reductions as alternative is chosen over baseline. Positive $\mathrm{PCI}$ means increase in environmental impacts and cost when switching from baseline to alternative.

Using data for more than 1,000 real-world truck activities integrated with our parametric LCA model, we identified necessary conditions for electric trucks to be cost-effective and robust. For the niche application of urban-type routes, electric trucks provide $6-15 \%$ reduction in overall life cycle cost compared to petroleum diesel. The benefits are robust under numerous uncertainties and in many areas of the U.S. For electric trucks to definitely outperform other options in typical operating conditions 
beyond the niche application, current electric truck capital costs must drop by $30-50 \%$; diesel fuel prices must be in the range of $6.5-8.1 \$$ /gallon; or carbon emissions reduction must be credited by $\$ 300-\$ 2,000$ per metric ton of carbon dioxide. Whether GHG or air pollutants, monetizing and internalizing potential emissions reduction benefit of electric trucks does not sufficiently compensate the lack of cost-effectiveness for most applications.

Electric trucks provide robust life cycle energy use and GHG emissions reduction benefits for both niche and average application. However, the complexity of energy-carbon-water nexus can create a trade-off between carbon emissions and water use reductions. Other than GHG emissions, CNG-powered ICE trucks are generally superior to the other technologies in terms of water use, acidification, and smog formation. However, similar environmental benefits can be achieved by electrification. Using marginal (instead of average) factors for electric grid does produce different life cycle inventory results, but it doesn't flip the overall comparisons of electric and non-electric technologies. Despite different sensitivities for different technologies, improving driving behavior universally reduces cost and environmental impacts.

\section{Acknowledgement}

We thank Adam Duran and Robert Prohaska of the National Renewable Energy Laboratory (NREL) for providing electric truck charging profiles. Jeff Gonder of the NREL and Dominik A. Karbowski of Argonne National Laboratory (ANL) generously helped us collect medium-duty truck drive cycles. We appreciate helpful discussions on power generation modeling with Stan Hadley of Oak Ridge National Laboratory (ORNL). We also acknowledge Dr. Frank Southworth and Dr. Marilyn A. Brown at the Georgia Institute of Technology for their thoughtful comments and valuable suggestions on the manuscript, truck activity modeling, and the impact of future power sector evolution. This work is solely based on the authors' research done at the Georgia Institute of Technology, which was supported by a grant from the National Science Foundation (award number 1441208). Dong-Yeon (D-Y) Lee was a post-doctoral scholar of Argonne National Laboratory during completion and publication of the manuscript. The views expressed in this work are those of the authors and do not necessarily reflect the views of Argonne National Laboratory or the National Science Foundation. 


\section{References}

40 CFR part 1066. Vehicle Testing Procedures. Retrieved from: http://www.gpo.gov/fdsys/pkg/CFR2012-title40-vol34/pdf/CFR-2012-title40-vol34-part1066.pdf (Accessed March 5, 2013).

AAA. (2015). Fuel Gauge Report. Retrieved from: www.FuelGaugeReport.AAA.com (Accessed October $30,2015)$.

André, M. (2004). The ARTEMIS European driving cycles for measuring car pollutant emissions. Science of the Total Environment, 334-33573-84. doi:10.1016/j.scitotenv.2004.04.070.

Aneja, V. P. and 64 researchers. (2016). Letter to the Senate on carbon neutrality of forest biomass. Woods Hole Research Center. February 22, 2016.

Allison Transmission. (2015). Allison Transmission Parts and Service. Retrieved from: http://www.allisontransmission.com/parts-service (Accessed August 2, 2015).

American Transportation Research Institute (ATRI). (2013). An Analysis of the Operational Costs of Trucking: A 2013 Update. Retrieved from: www.atri-online.org (Accessed January 16, 2014)

Argonne National Laboratory (ANL). (2013). Alternative Fuel Life-Cycle Environmental and Economic Transportation (AFLEET). Retrieved from: https://greet.es.anl.gov/afleet (Accessed November 3, 2014).

Argonne National Laboratory (ANL). (2014). Advanced Powertrain Research Facility - Downloadable Dynamometer Database $\left(D^{3}\right)$. Retrieved from: http://www.transportation.anl.gov/D3/ (accessed September 20, 2014).

Argonne National Laboratory (ANL). (2015). Greenhouse gases, Regulated Emissions, and Energy use in Transportation model (GREET). Retrieved from: http://greet.es.anl.gov (Accessed November 5, 2015).

Assessment and Reliability of Transport Emission Models and Inventory Systems (ARTEMIS). (2006). Drive Cycles. Retrieved from: http://www.inrets.fr/ur/lte/publiautresactions/fichesresultats/ficheartemis/road3/method31/All Cycles in Artemis BD 092006.xls (Accessed June 25, 2012).

Bachmann, C., Chingcuanco, F., MacLean, H., \& Roorda, M. J. (2015). Life-Cycle Assessment of DieselElectric Hybrid and Conventional Diesel Trucks for Deliveries. Journal of Transportation Engineering, 141(4), -1. doi:10.1061/(ASCE)TE.1943-5436.0000761.

Bare, J. C., Norris, G. A., Pennington, D. W., \& McKone, T. (2002). TRACl - The Tool for the Reduction and Assessment of Chemical and Other Environmental Impacts. Journal of Industrial Ecology, 6(3/4), 49.

Bare, J. (2011). TRACI 2.0: the tool for the reduction and assessment of chemical and other environmental impacts 2.0. Clean Technologies \& Environmental Policy, 13(5), 687-696. doi:10.1007/s10098-010-0338-9. 
Bare, J. C. (2012). Tool for the Reduction and Assessment of Chemical and other Environmental Impacts (TRACI), Software Name and Version Number: TRACI Version 2.1 - User's Manual.

Barnitt, R. (2011). Medium-and Heavy-Duty Electric Drive Vehicle Simulation and Analysis. DOE VTP Annual Merit Review. Retrieved from:

http://www1.eere.energy.gov/vehiclesandfuels/pdfs/merit review 2011/veh sys sim/vss043 barnitt 2011 o.pdf (Accessed December 10, 2013).

Bureau of Transportation Statistics (BTS). (2015). National Transportation Statistics. U.S. Department of Transportation. October 4, 2015. Retrieved from:

http://www.rita.dot.gov/bts/sites/rita.dot.gov.bts/files/publications/national transportation statistics/i ndex.html.

Burton, J., Walkowicz, K., Sindler, P., \& Duran, A. (2013a). In-Use and Vehicle Dynamometer Evaluation and Comparison of Class 7 Hybrid Electric and Conventional Diesel Delivery Trucks. SAE 2013 Commercial Vehicle Engineering Congress. doi: 10.4271/2013-01-2468.

Burton, E., Gonder, J., Wood, E. (2013b). Map Matching and Real World Integrated Sensor Data Warehousing. Federal Committee on Statistical Methodology (FCSM) Research Conference. November 46, 2013. Washington, DC. Retrieved from: www.nrel.gov/fleet dna (Accessed February 22, 2014).

California Air Resources Board (CARB). (2008). Staff Report: Initial Statement of Reasons for Proposed Rulemaking Proposed Regulation for In-Use On-Road Diesel Vehicles. Appendix J - Cost and Economic Analysis Methodology. Retrieved from: http://www.arb.ca.gov/regact/2008/truckbus08/appj.pdf (Accessed April 24, 2014).

California Air Resources Board (CARB). (2015). Staff Report: Initial Statement of Reasons for Proposed Rulemaking: Re-Adoption of the Low Carbon Fuel Standard. Released on January 2, 2015.

Camuzeau, J. R., Alvarez, R. A., Brooks, S. A., Browne, J. B., \& Sterner, T. (2015). Influence of Methane Emissions and Vehicle Efficiency on the Climate Implications of Heavy-Duty Natural Gas Trucks.

Environmental Science \& Technology, 49(11), 6402-6410. doi:10.1021/acs.est.5b00412.

Carnegie Mellon University Green Design Institute (CMU GDI). (2008). Economic Input-Output Life Cycle Assessment (EIO-LCA), US 1997 Industry Benchmark model. Retrieved from: http://www.eiolca.net (Accessed April 23, 2012).

Clark, N. N., Vora, K. A., Gautam, M., Wayne, W. S., \& Thompson, G. J. (2010). Expressing Cycles and Their Emissions on the Basis of Properties and Results from Other Cycles. Environ. Sci. Technol. 2010, 44, 5986-5992.

Cummins. (2015). Cummins Engines and Emissions Solutions. Retrieved from: http://www.cummins.com (Accessed July 13, 2015).

Davis, B. A. \& Figliozzi, M. A. (2013). A methodology to evaluate the competitiveness of electric delivery trucks. Transportation Research Part E, 498-23. doi:10.1016/j.tre.2012.07.003. 
Davis, S. C. \& Diegel, S. W. (2015). Transportation Energy Data Book: Edition 34. Oak Ridge National Laboratory. August 2015.

Deal, A. L. (2012). What Set of Conditions Would Make the Business Case to Convert Heavy Trucks to Natural Gas? A Case Study. National Energy Policy Institute (NEPI). Retrieved from:

http://www.tagnaturalgasinfo.com/uploads/1/2/2/3/12232668/natural gas for heavy trucks.pdf

(Accessed December 22, 2014).

Delorme, A. and Karbowski, D. (2010). Impact of Advanced Technologies on Medium-Duty Trucks Fuel Efficiency. SAE Technical Paper 2010-01-1929, 2010, doi:10.4271/2010-01-1929.

Department of Energy (DOE). (2016). Alternative Fuel Price Report. Retrieved from:

http://www.afdc.energy.gov/fuels/prices.html (Accessed January 15, 2016).

Dunn, J. B., Mueller, S., Kwon, H.-Y., \& Wang, M. Q. (2013). Land-use change and greenhouse gas emissions from corn and cellulosic ethanol. Biotechnology for Biofuels 2013, 6:51.

Duran, A. and Walkowicz, K. (2013). A Statistical Characterization of School Bus Drive Cycles Collected via Onboard Logging Systems. SAE Int. J. Commer. Veh. 6(2):400-406, 2013, doi:10.4271/2013-01-2400.

Duran, A., Ragatz, A., Prohaska, R., Kelly, K., \& Walkowicz, K. (2014). Characterization of in-use medium duty electric vehicle driving and charging behavior. 2014 IEEE International Electric Vehicle Conference (IEVC), 1. doi:10.1109/IEVC.2014.7056213.

Eaton. (2014). Eaton - Hybrid Power Systems. Retrieved from:

http://www.eaton.com/Eaton/ProductsServices/Vehicle/Hybrid-Power-Systems/index.htm (Accessed January 12, 2014).

Elgowainy, A., Han, J., Cai, H., Wang, M., Forman, G., \& Divita, V. (2014). Energy efficiency and greenhouse gas emission intensity of petroleum products at U.S. refineries. Environmental Science \& Technology, 48(13), 7612-24.

Elshout, P. M. F., van Zelm, R., Balkovic, J., Obersteiner, M., Schmid, E., Skalsky, R., van der Velde, M., \& Huijbregts, M. A. J. (2015). Greenhouse-gas payback times for crop-based biofuels. Nature Climate Change. Vol. 5, 604-610. June 2015.

Energy Information Administration (EIA). (2015a). Monthly Energy Review. Retrieved from: http://www.eia.gov/totalenergy/data/monthly (Accessed November 1, 2015).

Energy Information Administration (EIA). (2015b). Annual Energy Outlook 2015. Retrieved from: http://www.eia.gov/forecasts/aeo (Accessed August 20, 2015).

Energy Information Administration (EIA). (2015c). Electricity Data. Retrieved from: http://www.eia.gov/electricity/data.cfm (Accessed September 12, 2015).

Environmental Protection Agency (EPA). (1993). Federal Test Procedure Review Project: Preliminary Technical Report. EPA 420-R-93-007. 
Environmental Protection Agency (EPA). (2012a). Proposed Exhaust Emission Rates for Compressed Natural Gas Transit Buses in MOVES2013. MSTRS MOVES Review Work Group. September 25, 2012. Retrieved from: http://www3.epa.gov/otaq/models/moves/documents/faca-meeting-sep2012/05-cngbuses.pdf (Accessed April 16, 2013).

Environmental Protection Agency (EPA). (2012b). MOVES Work Group: Meeting Summary. Mobile Sources Technical Review Subcommittee. Retrieved from:

http://www.epa.gov/otaq/models/moves/documents/faca-meeting-sep2012/meeting-summary-sep25-2012.pdf (Accessed October 20, 2013).

Environmental Protection Agency (EPA). (2014). Motor Vehicle Emission Simulator (MOVES). Retrieved from: http://www.epa.gov/otaq/models/moves/ (Accessed December 20, 2014).

Environmental Protection Agency (EPA). (2015a). Light-Duty Automotive Technology, Carbon Dioxide Emissions, and Fuel Economy Trends: 1975 - 2015. Retrieved from:

https://www3.epa.gov/otaq/fetrends.htm (Accessed July 25, 2015).

EPA (Environmental Protection Agency). (2015b). Continuous Emissions Monitoring (CEM). Retrieved from: http://www.epa.gov/airmarkt/emissions/continuous-factsheet.html (Accessed October 3, 2015).

EPA (Environmental Protection Agency). (2015c). National Emissions Inventory (NEI). Retrieved from: http://www3.epa.gov/ttnchie1/eiinformation.html (Accessed September 22, 2015).

EPA (Environmental Protection Agency). (2015d). SmartWay Transport Partnership. Retrieved from: http://www3.epa.gov/smartway/ (Accessed October 4, 2015).

EPA (Environmental Protection Agency). (2016). Greenhouse Gas Emissions and Fuel Efficiency Standards for Medium- and Heavy-Duty Engines and Vehicles - Phase 2. Final Rule. Retrieved from:

https://www3.epa.gov/otaq/climate/documents/2016-08-ghg-hd-final-rule-phase2-preamble.pdf (Accessed August 20, 2016).

Fairley, P. (2011). Electric Vehicles Finally Succeed? Technology Review, February, 2011. Retrieved from: http://www.technologyreview.com/energy/26946 (Accessed July 14, 2011).

Federal Energy Regulatory Commission (FERC). (2015). FERC Forms. Retreived from: http://www.ferc.gov/docs-filing/forms.asp (Accessed September 10, 2015).

Federal Highway Administration (FHWA). (2004). The Next Generation Simulation (NGSIM) Program. Department of Transportation. Retrieved from: http://ngsim-community.org/ (Accessed September 30, 2013).

Federal Register. (2010). 40 CFR Part 80. Regulation of Fuels and Fuel Additives: Changes to Renewable Fuel Standard Program; Final Rule. Part II. March 26, 2010.

Federal Register. (2015a). Vol. 80, No. 133. Greenhouse Gas Emissions and Fuel Efficiency Standards for Medium- and Heavy-Duty Engines and Vehicles - Phase 2; Proposed Rule. July 13, 2015. 
Federal Register. (2015b). Carbon Pollution Emission Guidelines for Existing Stationary Sources: Electric Utility Generating Units; Final Rule. 40 CFR Part 60. RIN 2060-AR33. August 3, 2015.

Freightliner. (2014). Freightliner Product Literature. Retrieved from:

http://www.freightlinertrucks.com/Multimedia/MediaLibrary/Trucks/ (Accessed December 29, 2013).

Gaines, L., Stodolsky, F., \& Cuenca, R. (1998). Life-Cycle Analysis for Heavy Vehicles. Argonne National Laboratory. 1998. Retrieved from: http://www.transportation.anl.gov/pdfs/TA/102.pdf (Accessed September 25, 2012).

Gibson, B. E. \& Adamson, K. (2013). Emerging Battery Technologies. Navigant Consulting, Inc. Retrieved from: http://www.navigantresearch.com/research/emerging-battery-technologies (Accessed January 3, 2014).

Howarth, R. W., Santoro, R., \& Ingraffea, A. (2011). Methane and the greenhouse-gas footprint of natural gas from shale formations. Climatic Change, 106(4), 679-690. doi:10.1007/s10584-011-0061-5.

Huai, T., Shah, S., Wayne Miller, J., Chernich, D., Ayala, A., \& Younglove, T. (2006). Analysis of heavy-duty diesel truck activity and emissions data. Atmospheric Environment, 40(13), 2333-2344.

doi:10.1016/j.atmosenv.2005.12.006.

ImagineMade. (2014). Advanced Vehicle Simulator (ADVISOR). Retrieved from: http://advvehiclesim.sourceforge.net/ (Accessed April 16, 2014). Originally developed by NREL; license once managed by Big Ladder Software; and now an open source project.

Intergovernmental Panel on Climate Change (IPCC). (2013). Fifth Assessment Report (AR5). Retrieved from: https://www.ipcc.ch (Accessed April 5, 2014).

Jimenez, J. L. (1999). Understanding and Quantifying Motor Vehicle Emissions with Vehicle Specific Power and TILDAS Remote Sensing. PhD Dissertation. Department of Mechanical Engineering, Massachusetts Institute of Technology.

Kenworth. (2014). Medium Duty Body Builder's Manual. Retrieved from: http://www.kenworth.com/trucks (Accessed November 11, 2013).

LaClair, T. (2012). Application of a Tractive Energy Analysis to Quantify the Benefits of Advanced Efficiency Technologies for Medium- and Heavy-Duty Trucks Using Characteristic Drive Cycle Data. SAE Int. J. Commer. Veh. 5(1):141-163, 2012, doi:10.4271/2012-01-0361.

LaClair, T. J., Gao, Z., Fu, J., Calcagno, J., Yun, J. (2014). Development of a Short-Duration Drive Cycle to Represent Long-Term Measured Drive Cycle Data for the Evaluation of Truck Efficiency Technologies in Class 8 Tractor-Trailers. The 93rd Transportation Research Board Annual Meeting.

Lascurain, B. (2008). Class-8 Heavy Truck Duty Cycle Project Final Report. Oak Ridge National Laboratory. ORNL/TM-2008/122. 
Lascurain, M. B., Franzese, O., Capps, G., Siekmann, A., Thomas, N., LaClair, T., Barker, A., Knee, H. (2012). Medium Truck Duty Cycle Data from Real-World Driving Environments: Project Final Report. Oak Ridge National Laboratory. ORNL/TM-2012/240.

Lee, D.-Y., Thomas, V. M., \& Brown, M. A. (2013). Electric Urban Delivery Trucks: Energy Use, Greenhouse Gas Emissions, and Cost-Effectiveness. Environmental Science \& Technology, 47(14), 80228030. doi:10.1021/es400179w.

Luxfer. (2013). Cylinders for Natural Gas Vehicles. Retrieved from: http://www.luxfercylinders.com (Accessed February 20, 2015).

McManus, M. C. \& Taylor, C. M., (2015). The Changing Nature of Life Cycle Assessment. Biomass and Bioenergy, 82, Pp. 13-26.

Marriott, J., \& Matthews, H. S. (2005). Environmental effects of interstate power trading on electricity consumption mixes. Environmental Science \& Technology, 39(22), 8584-8590.

Muller, N. (2011). Air Pollution Emission Experiments and Policy analysis (APEEP) Model. Retrieved from: https://sites.google.com/site/nickmullershomepage/home/ap2-apeep-model-2 (Accessed September 1, 2015).

National Renewable Energy Laboratory (NREL). (2014). Transportation Secure Data Center (TSDC). Retrieved from: http://www.nrel.gov/transportation/secure transportation data.html (Accessed March 21, 2014).

National Renewable Energy Laboratory (NREL). (2015). System Advisor Model (SAM). Retrieved from: https://sam.nrel.gov/ (Accessed July 30, 2015).

Nellums, R., Steffen, J., \& Naito, S. (2003). Class 4 Hybrid Electric Truck for Pick Up and Delivery Applications. SAE Technical Paper 2003-01-3368, 2003, doi:10.4271/2003-01-3368.

Noel, G., J. \& Wayson, R. (2012). MOVES2010a Regional Level Sensitivity Analysis. OMB No. 0704-0188. Volpe National Transportation Systems Center. Federal Highway Administration. US DOT.

O'Keefe, M., Simpson, A., Kelly, K., \& Pedersen, D. (2007). Duty Cycle Characterization and Evaluation Towards Heavy Hybrid Vehicle Applications. SAE Technical Paper 2007-01-0302, 2007, doi:10.4271/2007-01-0302.

OPIS (Oil Price Information Service). (2016). Oil Price Information Service. Retrieved from: www.opisnet.com (Accessed May 14, 2016).

Plevin, R., Delucchi, M., \& Creutzig, F. (2014). Using Attributional Life Cycle Assessment to Estimate Climate-Change Mitigation Benefits Misleads Policy Makers. Journal of Industrial Ecology, 18(1), 73-83.

Porter, E. (2015). A Biofuel Debate: Will Cutting Trees Cut Carbon? The New York Times. February 10, 2015. 
Ross, M. (1994). Automobile Fuel Consumption and Emissions: Effects of Vehicle and Driving Characteristics. Ann. Rev. Energy Environ. 1994, 19:75 - 112.

Sankey, P., Clark, D. T., \& Micheloto, S. (2011). The End of the Oil Age. 2011 and Beyond: A Reality. Deutsche Bank Securities Inc., December 22, 2010. Retrieved from: http://gm.db.com (Accessed August 20, 2012).

Schwietzke, S., Griffin, W. M., Matthews, H. S., \& Bruhwiler, L. P. (2014). Natural gas fugitive emissions rates constrained by global atmospheric methane and ethane. Environmental Science \& Technology, 48(14), 7714-7722. doi:10.1021/es501204c.

Searchinger, T. D. \& Heimlich, R. (2008). Estimating Greenhouse Gas Emissions from Soy-based US Biodiesel when Factoring in Emissions from Land Use Change. Proceedings of a conference - The lifecycle carbon footprint of biofuels. January 29, 2008, in Miami Beach, FL.

Searchinger, T., Heimlich, R., Houghton, A., Dong, F., Elobeid, A., Fabiosa, J., Tokgoz, S., Hayes, D., Yu, T.H. (2008). Use of U.S. Croplands for Biofuels Increases Greenhouse Gases Through Emissions from LandUse Change. Science 319 (5867), 1238-1240.

Siler-Evans, K., Azevedo, I. L., \& Morgan, M. G. (2012). Marginal emissions factors for the U.S. electricity system. Environmental Science \& Technology, 46(9), 4742-4748. doi:10.1021/es300145v.

Smith Electric Vehicles (SEV). (2014). Smith Vehicles - Models and Configurations. Retrieved from: http://www.smithelectric.com/ (Accessed August 20, 2014).

Steinmann, Z. N., Venkatesh, A., Hauck, M., Schipper, A. M., Karuppiah, R., Laurenzi, I. J., \& Huijbregts, M. J. (2014). How to address data gaps in life cycle inventories: a case study on estimating CO2 emissions from coal-fired electricity plants on a global scale. Environmental Science \& Technology, 48(9), 5282-5289. doi:10.1021/es500757p.

The White House. (2013). Technical Support Document: Technical Update of the Social Cost of Carbon for Regulatory Impact Analysis under Executive Order 12866. Interagency Working Group on Social Cost of Carbon, United States Government. Retrieved from:

http://www.whitehouse.gov/sites/default/files/omb/assets/inforeg/technical-update-social-costofcarbon-for-regulator-impact-analysis.pdf (Accessed July 27, 2014).

Tyner, W. E. (2016). Testimony on the U.S. Renewable Fuel Standard before the U.S. House of Representatives Committee on Oversight and Government reform, Subcommittee on the Interior and the Subcommittee on Healthcare, Benefits, and Administrative Rules. March 16, 2016. Retrieved from: https://oversight.house.gov/wp-content/uploads/2016/03/2016-03-16-Wallace-Tyner-Testimony.pdf (Accessed June 25, 2016).

Walkowicz, K., Kelly, K., Duran, A., \& Burton, E. (2014). Fleet DNA Project Data. National Renewable Energy Laboratory. http://www.nrel.gov/fleetdna. 
Wang, M., Huo, H., \& Arora, S. (2011). Methods of dealing with co-products of biofuels in life-cycle analysis and consequent results within the U.S. context. Energy Policy, 39 (Sustainability of biofuels), 5726-5736. doi:10.1016/j.enpol.2010.03.052.

Watson, H., Milkins, E., Preston, M., Chittleborough, C. Alimoradian, B. (1983). Predicting Fuel Consumption and Emissions-Transferring Chassis Dynamometer Results to Real Driving Conditions. SAE Technical Paper 830435, 1983, doi:10.4271/830435.

Wayne, W. S., Clark, N. N., Nine, R. D., \& Elefante, D. (2004). A Comparison of Emissions and Fuel Economy from Hybrid-Electric and Conventional-Drive Transit Buses. Energy and Fuels, 18257-270.

West Virginia University (WVU). (2014). Integrated Bus Information System (IBIS): http://ibis.wVu.edu (Accessed December 15, 2014).

Yang, Y. (2016). Two Sides of the Same Coin: Consequential Life Cycle Assessment based on the Attributional Framework. Journal of Cleaner Production 127 (2016): 274-81.

Yoon, S., Collins, J., Thiruvengadam, A., Gautam, M., Herner, J., \& Ayala, A. (2013). Criteria pollutant and greenhouse gas emissions from CNG transit buses equipped with three-way catalysts compared to leanburn engines and oxidation catalyst technologies. Journal of the Air \& Waste Management Association (1995), 63(8), 926-933. 